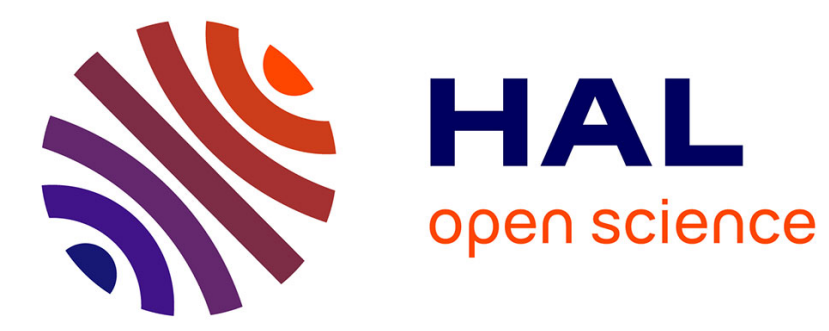

\title{
Collisional and alteration history of the CM parent body
} Lionel Vacher, Yves Marrocchi, Johan Villeneuve, Maximilien

\author{
Verdier-Paoletti, Matthieu Gounelle
}

\section{To cite this version:}

Lionel Vacher, Yves Marrocchi, Johan Villeneuve, Maximilien Verdier-Paoletti, Matthieu Gounelle. Collisional and alteration history of the CM parent body. Geochimica et Cosmochimica Acta, 2018, 239, pp.213-234. 10.1016/j.gca.2018.08.006 . hal-02357533

\section{HAL Id: hal-02357533 \\ https://hal.univ-lorraine.fr/hal-02357533}

Submitted on 10 Nov 2019

HAL is a multi-disciplinary open access archive for the deposit and dissemination of scientific research documents, whether they are published or not. The documents may come from teaching and research institutions in France or abroad, or from public or private research centers.
L'archive ouverte pluridisciplinaire HAL, est destinée au dépôt et à la diffusion de documents scientifiques de niveau recherche, publiés ou non, émanant des établissements d'enseignement et de recherche français ou étrangers, des laboratoires publics ou privés. 
Clasts, calcite, aragonite, oxygen and carbon isotopes, impacts, X-ray tomography

\section{Collisional and alteration history of the CM parent body}

Lionel G. Vacher ${ }^{\mathrm{a}^{*}}$, Yves Marrocchi ${ }^{\mathrm{a}}$, Johan Villeneuve ${ }^{\mathrm{a}}$, Maximilien J. Verdier-Paoletti ${ }^{\mathrm{b}}$ and Matthieu Gounelle ${ }^{\mathrm{c}, \mathrm{d}}$

${ }^{a}$ CRPG, CNRS, Université de Lorraine, UMR 7358, Vandoeuvre-les-Nancy, F-54501, France ${ }^{\mathrm{b}}$ Department of Terrestrial Magnetism, Carnegie Institution of Washington, 5241 Broad Branch Road NW, Washington, DC 20015, USA

'IMPMC, MNHN, Sorbonne Universités, UMR CNRS 7590, 57 rue Cuvier, 75005 Paris, France

${ }^{\mathrm{d}}$ Institut Universitaire de France, Maison des Universités, 103 boulevard Saint-Michel, 75005 Paris, France

*Corresponding author: lvacher@crpg.cnrs-nancy.fr

18 


\section{ABSTRACT}

Boriskino is a little studied CM2 chondrite composed of millimeter-sized clasts of different lithologies and degrees of alteration. Boriskino thus offers a good opportunity to better understand the preaccretionary alteration history and collisional evolution that took place on the CM parent body. The least altered lithology displays ${ }^{16} \mathrm{O}$-poor Type 1a calcite and aragonite grains $\left(\delta^{18} \mathrm{O} \approx 30-37 \%\right.$, $\delta^{17} \mathrm{O} \approx 15-18 \%$ and $\Delta^{17} \mathrm{O} \approx-2$ to $0 \%$ o, SMOW) that precipitated early, before the establishment of the petrofabric, from a fluid whose isotopic composition was established by isotopic exchange between a ${ }^{16} \mathrm{O}$-poor water and ${ }^{16} \mathrm{O}$-rich anhydrous silicates. In contrast, the more altered lithologies exhibit ${ }^{16} \mathrm{O}$-rich Type $2 \mathrm{a}$ and veins of calcite $\left(\delta^{18} \mathrm{O} \approx 17-23 \%\right.$, $\delta^{17} \mathrm{O} \approx 6-9 \%$ and $\Delta^{17} \mathrm{O} \approx-4$ to $-1 \%$, SMOW $)$ that precipitated after establishment of the deformation, from transported ${ }^{16} \mathrm{O}$-rich fluid in preexisting fractures. From our petrographic and X-ray tomographic results, we propose that the more altered lithologies of Boriskino were subjected to high intensity impact(s) (10-30 GPa) that produced a petrofabric, fractures and chondrule flattening. Taking all our results together, we propose a scenario for the deformation and alteration history of Boriskino, in which the petrographic and isotopic differences between the lithologies are explained by their separate locations into a single $\mathrm{CM}$ parent body. Based on the $\delta^{13} \mathrm{C}-\delta^{18} \mathrm{O}$ values of the Boriskino Type 2 a calcite $\left(\delta^{13} \mathrm{C} \approx 30-71 \%\right.$, PDB $)$, we propose an alternative $\delta^{13} \mathrm{C}-\delta^{18} \mathrm{O}$ model where the precipitation of Type $2 \mathrm{a}$ calcite can occurred in an open system environment with the escape of ${ }^{13} \mathrm{C}$-depleted $\mathrm{CH}_{4}$ produced from the reduction of C-bearing species by $\mathrm{H}_{2}$ released during serpentinization or kamacite corrosion. Assuming a mean precipitation temperature of $110^{\circ} \mathrm{C}$, the observed $\delta^{13} \mathrm{C}$ variability in $\mathrm{T} 2 \mathrm{a}$ calcite can be reproduced by the escape of $\approx 15-50 \%$ of dissolved carbon into $\mathrm{CH}_{4}$ by Rayleigh distillation. 
The CM carbonaceous chondrites are samples of dark primitive C-type asteroids (Clark et al., 2010; Cloutis et al., 2011) accreted closed to the snowline (Morbidelli et al., 2016) and that contain a high proportion of water (i.e. water/rock ratio $=0.4$; Marrocchi et al., 2018), mainly in hydroxyl form in the matrix (Rubin et al., 2007). Their mineralogy and petrography suggest they have undergone brecciation and low temperature hydrothermal alteration, which could have been induced by low velocity impacts and/or by heat released by the decay of the

${ }^{26} \mathrm{Al}$, respectively (Dufresne and Anders, 1962; Metzler et al., 1992; Zolensky et al., 1997;

Nakamura, 2005; Rubin et al., 2007; Nakato et al., 2008). CM chondrites experienced 55 different degrees of aqueous alteration, from moderate (CM2) to high (CM1), as reflected by their varying proportion of secondary phases, including $\mathrm{Fe}-\mathrm{Mg}$ - and S-rich phyllosilicates (e.g., sulfide-hydroxide/cronstedtite association, hereafter referred as TCI), Fe-Ni sulfides, and carbonates (McSween, 1979; Bunch and Chang, 1980; Tomeoka and Buseck, 1985; Zolensky et al., 1997; Brearley, 2006; Rubin et al., 2007; Howard et al., 2009, 2015; Hewins et al., 2014; Lee et al., 2014; Pignatelli et al., 2016, 2017; Rubin and Ma, 2017).

Carbonates are ubiquitous in CMs and represent a minor proportion of secondary mineral assemblages (i.e., up to 2-3 vol.\%; Marrocchi et al., 2014; Lee et al., 2014). Their mineralogy provides information about the chemical evolution of the fluid during aqueous alteration. For example, Ca-carbonates occur as aragonite and calcite in most CM2 chondrites, whereas dolomites are only found in the more altered CM chondrites (Johnson and Prinz, 1993; Riciputi et al., 1994; Browning and Bourcier, 1998; Benedix et al., 2003; De Leuw et al., 2010; Lee et al., 2012; Lee et al., 2014; Tyra et al., 2016; Vacher et al., 2017). Furthermore, their oxygen isotopic compositions (i.e., $\delta^{17,18} \mathrm{O}$ ) can be used to decipher their precipitation temperature and the origin and evolution of the fluid. Based on the O-isotopic 
compositions of Ca-carbonates, it has been proposed (i) that they precipitated at varying temperatures, in the range $0-300^{\circ} \mathrm{C}$ (Clayton and Mayeda, 1984; Benedix et al., 2003; Guo and Eiler, 2007; Alexander et al., 2015; Verdier-Paoletti et al., 2017a), (ii) that aqueous alteration processes occurred essentially in a closed system with a static fluid interacting with anhydrous silicates (DuFresne and Anders, 1962; Clayton and Mayeda, 1999; Benedix et al., 2003) and (iii) that the least altered CMs (i.e., Paris and Maribo) accreted a significant proportion of ${ }^{17,18}$ O-rich water inherited from the outer Solar System (Horstmann et al., 2014; Vacher et al., 2016). Carbon isotopic composition of carbonates $\left(\delta^{13} \mathrm{C}\right)$ also reflects aqueous alteration and can constrain the origin of dissolved carbon into the fluid. From bulk and in situ C-isotopic compositions of $\mathrm{CM}$ carbonates, it has been postulated that carbonates precipitated from C-bearing inorganic molecules (i.e., $\mathrm{CO}$ or $\mathrm{CO}_{2}$; Alexander et al., 2015) or soluble organic matter (SOM) (Vacher et al., 2017). C-isotopes can also be affected by different fractionation mechanisms, such as escape of C-bearing gas (e.g., $\mathrm{CH}_{4}$, Guo and Eiler, 2007) during, for example, venting event (Telus et al., 2017).

Carbonate precipitation in response to stress events, such as impacts or accretional/gravitational compaction (Cain et al., 1986; Fujimara et al., 1983) has previously been reported based on the presence of different petrographic features: e-twinned calcite, calcite veins and replacement of chondrules by calcite grains (Bunch and Chang, 1980; Benedix et al., 2003; Lee and Ellen, 2008; Lindgren et al., 2011; Tyra et al., 2012; Lee et al., 2014). Calcite veins show ${ }^{16} \mathrm{O}$-rich isotopic compositions that suggest late precipitation from evolved solutions (Lindgren et al., 2017). This assumption is consistent with a late carbonate precipitation event, during which the evolved fluid would have been mobilized from different region of the parent body or by dehydration of existing phyllosilicates (Rubin, 2012; Lee et al., 2013). In addition, it has been proposed that impacts could create open fracture networks and microcracks in $\mathrm{CM}$ chondrites that would facilitate the circulation of fluids (DeCarli et 
al., 2001; Rubin, 2012). Impact-induced formation of fractures and/or cracks has been reported in shock experiments involving carbonaceous chondrites (Nakamura et al., 1995; Tomeoka et al., 1999; Nakamura, 2000). These experiments also highlighted the formation of foliation petrofabrics of the chondritic particles (i.e., chondrules, calcium-aluminum-rich refractory inclusions, clumps of tochilinite-cronstedtite intergrowths, olivine grains and flattened aggregates) and the flattening of chondrules with the increase in impact intensity (Nakamura et al., 1995; Tomeoka et al., 1999; Nakamura, 2000). Preferential orientations have been observed in $\mathrm{CM}$ and $\mathrm{CV}$ chondrites with different degrees of foliation intensity (Rubin, 2012; Lindgren et al., 2015; Hanna et al., 2015). However, impact events are not the only processes able to create preferential orientation of particles; lithostatic compaction may also produce flattened chondrules and CAIs and crystallographic orientation of phyllosilicates and carbonates (Fujimura et al., 1983; Cain et al., 1986; Zolensky et al., 1997; Lee and Ellen, 2008; Lindgren et al., 2015). This latter process was likely involved in the establishment of the $\mathrm{CM}$ and $\mathrm{CV}$ petrofabrics as attested by (i) the occurrence of preferential orientation in poorly altered CM chondrites without fractures and carbonate veins (Lindgren et al., 2015; Hanna et al., 2015) and (ii) the lack of evidence for strong shock characteristics in some meteorites (Scott et al., 1992). In addition, CM chondrites were probably highly porous prior to their deformation (i.e., 30-50\%, Hanna et al., 2015), allowing the impact energy to be dissipated from the collapse of the pore spaces (Suttle et al., 2017). This inconsistency between a low shock-stage and evidence of compaction in CM chondrites (Lindgren et al., 2015) highlights that the relationship between aqueous alteration and stress deformation remains poorly understood.

Most of the CM chondrites are breccias and exhibit clats with various degrees of aqueous alteration (Rubin and Wasson, 1986; Metzler et al., 1992; Lindgren et al., 2013; Bischoff et al., 2017). These clasts provide important constraints on the post-accretionary 
120 alteration history and collisional activity of the CM chondrites (Lindgren et al., 2013). A

121 recent report of the carbonaceous chondrite Boriskino, a CM2 chondrite that fell in Russia in

122 1930, describes the presence of centimetric clasts with contains clasts with a variety of

123 lithologies (Verdier-Paoletti et al., 2017b), suggesting that this chondrite may provide a good

124 opportunity to better understand the link between aqueous alteration and the deformation

125 history of the CM chondrites that is not well investigated yet. The present study therefore

126 aims to (i) understand the preaccretional alteration history of CM chondrites by characterizing

127 clasts in CM2 Boriskino that exhibit different degrees of alteration, (ii) retrace the isotopic

128 evolution of the fluid from the $\mathrm{O} \& \mathrm{C}$-isotopic composition of Ca-carbonates, and

129 (iii) identify the mechanisms that induced preferential orientation and aqueous alteration in

130 CM chondrites. From a survey of two Boriskino polished sections, we adopt a multi-pronged

131 approach composed of petrographic observations, preferential orientation measurements on

132 chondritic particles, mineralogical identifications, and $\mathrm{O}$ and $\mathrm{C}$-isotopic measurements on $\mathrm{Ca}$ -

133 carbonates. We focus our attention on bulk Boriskino samples by performing X-ray computed

134 tomography to map flattening chondrules and measure their preferential orientation.

135 


\section{MATERIALS AND METHODS}

\section{2-1 SEM imaging, characterizations and petrofabric analyses}

141 (\#3788-3 and \#3788-4) from the Muséum National d'Histoire Naturelle of Paris (MNHN)

142 were made at the Centre de Recherches Pétrographique et Géochimiques (CRPG) using a

143 scanning electron microscope (SEM) JEOL JSM-6510 equipped with an energy dispersive X-

144 ray detector (Bruker-AXS XFlash, silicon drift detector: SDD). The SEM observations were

145 performed with a beam current of $3 \mathrm{nA}$ at $15 \mathrm{kV}$. The entire two polished sections were

146 mapped to produce the Back-Scattered Electron (BSE) mosaics. The modal abundance of

147 phases for each lithology was determined from the BSE mosaics using JMicroVision 148 software.

149 Using the BSE mosaics of the two polished sections, the petrofabric characteristics of 150 each clast were determined following the method of Rubin (2012). In order to compare the 151 median orientation of the petrofabrics within each polished section (i.e., \#3788-4), we 152 measured the tilt angle between an arbitrary reference (i.e., the horizontal $=0^{\circ}$ ) and the 153 primary axis length of each particle (i.e., chondrule, TCI clump and olivine grain). The tilt 154 angles were measured using Adobe Illustrator. We then estimated the standard deviation $(c)$ 155 of the petrofabric(s), the high maximum frequency (a) and the mean value of the Gaussian 156 curve (b) for each clast using a Gaussian fit on the data set $\left(y=a \times e^{\left(\frac{x-b}{c}\right)^{2}}\right)$. 

equipped with a 600 g.mm ${ }^{-1}$ grating and an Edge filter. The confocal hole aperture and slit aperture were $500 \mu \mathrm{m}$ and $100 \mu \mathrm{m}$, respectively. The excitation beam was produced by a $457.94 \mathrm{~nm}$ blue laser at a power of $\sim 20 \mathrm{~mW}$, focused on the sample using a $\times 100$ LWD IR objective (Olympus). The number of accumulations and the acquisition time were $2 \times 5 \mathrm{~s}$. The signal-to-noise ratio $(\mathrm{S} / \mathrm{N})$ was less than $1 \%$ of the signal. Calcite and aragonite were identified on the basis of their minor Raman bands; calcite has specific bands at 282 and 713 $\mathrm{cm}^{-1}$ while aragonite has bands at 207 and $704 \mathrm{~cm}^{-1}$ (White, 2009).

\section{2-3 Carbon and Oxygen isotopes}

The two polished sections were initially coated with carbon to measure oxygen isotopes. Oxygen isotopic compositions of Ca-carbonates were measured using a CAMECA ims $1280 \mathrm{HR} 2$ at CRPG (Nancy, France). ${ }^{16} \mathrm{O}^{-},{ }^{17} \mathrm{O}^{-}$, and ${ }^{18} \mathrm{O}^{-}$ions produced by a $\mathrm{Cs}^{+}$primary ion beam $(\approx 15 \mu \mathrm{m}$ spot size, $5 \mathrm{nA})$ were collected in multi-collection mode using three

174 Faraday cups. A normal-incidence electron gun was used for charge compensation. In order to

175 remove ${ }^{16} \mathrm{OH}^{-}$interference on the ${ }^{17} \mathrm{O}^{-}$peak and achieve maximum flatness on the top of the $176{ }^{16} \mathrm{O}^{-}$and ${ }^{18} \mathrm{O}^{-}$peaks, the entrance and exit slits of the central Faraday cup (80 and $173 \mu \mathrm{m}$, 177 respectively) were adjusted to obtain a Mass Resolving Power (MRP $=M / \Delta M)$ of $\approx 7000$ for

$178{ }^{17} \mathrm{O}^{-}$on the central Faraday cup. ${ }^{16} \mathrm{O}^{-}$and ${ }^{18} \mathrm{O}^{-}$were measured on L'2 and $\mathrm{H} 1$ (slit 1 , MRP $\approx$ 179 2500). Acquisition times were set so as to obtain counting statistics on the order of $\pm 0.2 \%$ $180(1 \sigma)$ for $\delta^{18} \mathrm{O}$ and $\delta^{17} \mathrm{O}$. We analysed three terrestrial standards: (i) quartz from Brazil $\left(\delta^{18} \mathrm{O}=\right.$ 181 $\left.9.6 \%,{ }^{16} \mathrm{O}=1.8 \times 10^{9} \mathrm{Cps}\right)$, (ii) forsterite from San Carlos $\left(\delta^{18} \mathrm{O}=5.5 \%\right.$, ${ }^{16} \mathrm{O}=1.7 \times 10^{9}$ 
$182 \mathrm{Cps}$ ), and (iii) calcite from Mexico (55.6 wt $\%$ of $\mathrm{CaO}$ and $0.03 \mathrm{wt} \%$ of $\mathrm{MgO}, \delta^{18} \mathrm{O}=23.6 \%$ 183 and ${ }^{16} \mathrm{O}=2.3 \times 10^{9} \mathrm{Cps}$, with a reproducibility $\left.0.3 \%, \mathrm{n}=26\right)$ to define the Instrumental Mass

184 Fractionation (IMF) for the three oxygen isotopes and correct for instrumental mass 185 fractionation for calcite. ${ }^{17} \mathrm{O} /{ }^{16} \mathrm{O}$ and ${ }^{18} \mathrm{O} /{ }^{16} \mathrm{O}$ isotope ratios were normalized using the

186 Standard Mean Ocean Water (SMOW). IMF for both calcite and aragonite was determined 187 from the same Mexico calcite standard because carbonate identification by Raman 188 spectroscopy was performed after isotopic measurements. It should be noted that the matrix 189 effect between calcite and aragonite is negligible (i.e., $\approx 1 \%$, Lécuyer et al., 2012) regarding 190 the precision of oxygen measurements by SIMS. In addition, the low $\mathrm{Fe}, \mathrm{Mg}$ and $\mathrm{Mn}$ content 191 in Boriskino's Ca-carbonate (i.e., < $1 \mathrm{wt} \%$, Verdier-Paoletti et al., 2017b) is not expected to 192 produce significant IMF (Rollion-Bard et al., 2007). Because IMF values of standards have 193 been observed to derived linearly over the time, we calculated the IMF value for each sample 194 analysis by interpolated its value during time (i.e., number of measurements). Typical 195 measurement errors $(2 \sigma)$, which took into account the errors in each measurement as well as 196 the external reproducibility of the standard, were estimated to be $\approx 0.7 \%$ for $\delta^{18} \mathrm{O}, \approx 0.6 \%$ o 197 for $\delta^{17} \mathrm{O}$, and $\approx 0.8 \%$ for $\Delta^{17} \mathrm{O}$ (where $\Delta^{17} \mathrm{O}$ represents the deviation from the TFL: $\Delta^{17} \mathrm{O}=$ $\left.198 \delta^{17} \mathrm{O}-0.52 \times \delta^{18} \mathrm{O}\right)$.

In order to avoid carbon contamination inherited from previous carbon coatings (i.e., 200 after the SEM and O-isotopes), sample surfaces were polished with liquid cerium oxide and 201 ultrasonically cleaned in ethanol for 5 min (Hanon et al., 1998). The samples were then coated 202 with gold $(\approx 50 \mathrm{~nm})$ in preparation for carbon isotope analysis using a CAMECA ims 1280 HR2 ion microprobe at CRPG-CNRS (Nancy, France). A Cs ${ }^{+}$primary Gaussian beam of $5 \mathrm{nA}$

204 was focused to produce a spot size of $\approx 20 \mu \mathrm{m}$. A normal-incidence electron gun was used for 205 charge compensation. The microprobe was specifically tuned to obtain a MRP of $\approx 5000$ so 206 that the ${ }^{12} \mathrm{CH}^{-}$contribution to ${ }^{13} \mathrm{C}$ could be eliminated. The settings of the entrance and 
multicollector slits (slit 2, Rollion-Bard et al., 2007) and the field aperture were $70 \mu \mathrm{m}, 240$

$208 \mu \mathrm{m}$ and $3000 \mu \mathrm{m}$, respectively. Carbon isotopes were measured in multi-collection mode 209 using two off-axis faraday cups, $\mathrm{C}$ and $\mathrm{H} 1$, with $10^{11}$ ohm resistors for ${ }^{12} \mathrm{C}$ and ${ }^{13} \mathrm{C}$, 210 respectively. Before each measurement, a presputtering step of 120 s with a raster of $20 \times 20$ $211 \mu \mathrm{m}$ was applied in order to remove any remaining traces of the carbon coating. The 212 acquisition time was 5 s long and repeated over 40 cycles and the typical internal error for 213 each measurement was $\approx 0.8 \%$ o $(2 \sigma)$ on $\delta^{13} \mathrm{C}$. A terrestrial calcite from New Caledonia's 214 carbonatite (55 wt $\%$ of $\mathrm{CaO}$ and $0.4 \mathrm{wt} \%$ of $\mathrm{MgO}, \delta^{13} \mathrm{C}=-5.39 \%$ o, ${ }^{12} \mathrm{C}=1.4 \times 10^{7} \mathrm{Cps}$, 215 Rollion-Bard et al., 2007, with a reproducibility of $0.2(n=15)$ and $0.6 \%(n=8)$ for sessions 2161 and 2, respectively) was used as a standard to correct for Instrumental Mass Fractionation 217 (IMF) for both calcite and aragonite. As for O-isotopes, C-isotopes could be affected by 218 matrix effect. However, the effect of chemical compositions and the aragonite/calcite IMF $(\approx$ 219 2\%o, Lécuyer et al., 2012) is supposed to be negligible considering: (i) the precision on SIMS 220 C-isotopic measurements (i.e., $\approx 1 \%$ ) and (ii) the large range of $\delta^{13} \mathrm{C}$ shown by Ca221 carbonates (i.e., 20-90\%). Isotopes ratios were normalized to Pee Dee Belemnite (PDB). Typical measurement errors $(2 \sigma)$, which took into account the errors in each measurement as well as the external reproducibility of the standard, were estimated to be $\approx 0.8 \%$ for $\delta^{13} \mathrm{C}$.

\section{2-4 X-ray computed tomography (XCT)}

A bulk sample of Boriskino with a mass of $328 \mathrm{mg}$ was subjected to X-ray computed tomography (XCT) imaging to provide a full 3D dataset of the sample (Fig. 1a). The CT imaging was made on the AST-RX platform of the Muséum National d'Histoire Naturelle of Paris (MNHN) using a GE Sensing and Inspection Technologies Phoenix|x-ray v|tome|x L240-180 CT scanner. We used the microfocus RX source at $240 \mathrm{kV} / 320 \mathrm{~W}$, detector $400 \times$ $400 \mathrm{~mm}$, with a matrix of 2024 pixels (pixel size: $200 \times 200$ microns). The settings 
233 parameters were as follows: voltage $=80 \mathrm{kV}$; current $=230 \mu \mathrm{A}$; exposure: $500 \mathrm{~ms}$; and 234 isotropic voxel size $=8 \mu \mathrm{m}$. Data were reconstructed using datos $\mid \mathrm{x}$ reconstruction software 235 (Phoenix|x-ray, release 2.0), then exported into a 16-bit TIFF image stack of 1740 virtual 236 slices in transverse view. In the full 3D data set of the sample, the grey level of each slice corresponds to the $\mathrm{X}$ 238 ray attenuation, which is related to density and the atomic number of the material. The darkest 239 pixels represent the least attenuating material or the lowest density (e.g., matrix and 240 chondrules) while the brightest pixels represent the most attenuating material or the highest 241 density (e.g., metal and sulphide grains). Thus, based on the grey level of each image, we 242 observed 61 elliptic dark-toned objects that we interpret as type I chondrules (Fig. 1b). We 243 painted all voxels into these chondrules on each step of 5 slices for the biggest objects and on 244 each slice for the smallest object with the Avizo ${ }^{\mathrm{TM}}$ software. Each chondrule was then modeled in 3D volume by interpolation of the painted voxels. Next, an ellipsoid was fitted to 246 each chondrule by merit function using Blob3D software package (Ketcham, 2005a, 247 Ketcham, 2005b). The orientation, axial length, aspect ratio and location of each ellipsoid 248 were measured (Table 2). Plunges, trends and eigenvectors $\left(\mathrm{v}_{1}, \mathrm{v}_{2}\right.$ and $\left.\mathrm{v}_{3}\right)$ of the raw data 249 were calculated and plotted on a stereogram with Stereonet software from the direction cosines given by the Blob3D results. The eigenvalues $\left(\lambda_{1}, \lambda_{2}\right.$ and $\left.\lambda_{3}\right)$ were also determined in 251 order to estimate whether the orientation of the ellipsoids were non-random and defined a 252 petrofabric, according to the method of (Woodcock and Naylor, 1983). In this method, two 253 parameters must be determined: (i) the shape parameter $(\mathrm{K})$, which ranges from $\mathrm{K}=0$ (girdle 254 distribution) to $\mathrm{K}>1$ (cluster distribution); and (ii) the strength parameter (C), which ranges 255 from $\mathrm{C} \approx 0$ (weak petrofabric) to $\mathrm{C}>4$ (strong petrofabric). 


\subsection{Petrography of Boriskino}

The two polished sections of Boriskino are composed of millimeter-sized clasts in direct

contact with each other, which can be distinguished by their petrography (Fig. 2). Among these clasts, we defined three lithologies (labeled 1 to 3 ) characterized by varying contents of

(i) phyllosilicate,

(ii) metallic iron,

(iii) sulfide,

and

(iv) different petrographic types of Ca-carbonates (Fig. 3, Table 1).

Lithology 1 is present in both sections of Boriskino and represents $88 \%$ and $24 \%$ of the sample's surface of section \#3 and \#4, respectively (Fig. 2a). This lithology is characterized by a moderate proportion of matrix and chondrules $(\approx 60.15$ vol. $\%$ and $\approx 30$ vol.\%, respectively), a high proportion of Fe-Ni sulphide grains ( $\approx 8.6$ vol.\%) and a low abundance of Ca-carbonates $(\approx 1.2$ vol.\%) and metallic Fe-Ni $(\approx 0.05$ vol.\%) (Table 1; Fig. 3a). Lithology 2 is only present in section \#4 and corresponds to $26 \%$ of the sample's surface, where it is found in two separated clasts. This lithology shows comparable proportions of 272 matrix, chondrules and Ca-carbonate relative to lithology $1(\approx 62.3$ vol. $\%, \approx 34.7$ vol. $\%$ and $\approx$ 2731.4 vol.\%, respectively) but a lower proportion of Fe-Ni sulphide (1.6 vol.\%) and a lack of Fe-Ni metal (Table 1; Fig. 3b). Lithology 3 is present in section \#4 and represents $22 \%$ of the sample's surface, and possibly in section \#3 although it is difficult to assess properly due to its low surface area (i.e., 5\%, Fig. 2). This lithology differs from the others in that it is 277 characterized by a high abundance of matrix and Ca-carbonate $(\approx 68.5$ vol. $\%$ and $\approx 2.4$ vol. $\%$, 278 respectively). It has a similar proportion of chondrules to lithology $1(\approx 23.9$ vol.\%), a moderate proportion of $\mathrm{Fe}-\mathrm{Ni}$ sulphide $(5.2 \mathrm{vol} . \%)$ and a high proportion of $\mathrm{Fe}-\mathrm{Ni}$ metal $(\approx$ 


\subsection{Ca-carbonate grains}

283

284

285

286

Twenty Ca-carbonate grains were observed in the three different lithologies of Boriskino (Fig. 2). They mainly occur as calcite in all three lithologies $(n=17$, Table 3), but a few grains of aragonite were also identified in lithology $3(n=4$, Table 3) (Fig. 2 \& 4). Based on the mineralogical classification of CM carbonates (Tyra et al., 2007; Tyra et al., 2012; Lee et al., 2014; Vacher et al., 2017), they can be classified into two types: (i) Type 1a grains, which are surrounded by a serpentine/tochilinite rim, and (ii) Type 2a grains, which have replaced primary minerals with inclusions of Fe-Ni sulphide inclusions.

3.2.1 Type 1a Ca-carbonates (represented in figures as green circles for calcite and diamonds for aragonite)

Type 1a Ca-carbonates (hereafter T1a) are scattered throughout the matrix of lithology 3 (Fig. 2a \& 2b). They mostly occur in the form of subhedral or anhedral single or polycrystalline grains with typical sizes in the range from a few tens to hundreds of micrometers (Fig. 4b). They are systematically partially or totally surrounded by a serpentine/tochilinite rim with an average thickness of a few micrometers (Fig. $4 \mathbf{a} \& \mathbf{4 b}$ ). These rims show irregular boundaries at the contacts with the host-grains. The proportions of T1a calcite and aragonite grains are similar, with a fraction of $\approx 66 \%$ of calcite $(n=5)$ and $\approx$ $44 \%$ of aragonite $(n=4)$. T1a Ca-carbonates have $\delta^{18} \mathrm{O}$ values ranging from 29.8 to $36.8 \%$ (mean of 33.9\%o, $\sigma=2.4 \%$ ), $\delta^{17} \mathrm{O}$ values from 15.2 to $18.3 \%$ (mean of $16.7 \%$, $\sigma=1 \%$ ) and variable $\Delta^{17} \mathrm{O}$ values, ranging from -1.8 to $-0.4 \%$ (mean of $-1 \%$ o, $\sigma=0.4 \%$ ) (Fig. 5, Table 3). Significant variation in $\mathrm{C}$ isotopes is also observed, with $\delta^{13} \mathrm{C}$ values between 18.3 and $91.8 \%$ o (mean of 55.8\%o, $\sigma=25.7 \%$ ). 
The Type $2 \mathrm{a}$ calcites (hereafter T2a) were all found in lithologies 1 and 2, with the exception of grain CC16, which was in lithology 3 (Fig. 2, Table 3). They occur as polycrystalline grains of hundreds of micrometers in size containing Fe-Ni sulphide inclusions of a few tens of micrometers in size (Fig. 4c). According to their location and morphology, T2a calcites can be divided into two groups: (i) polycrystalline aggregates located in the matrix, exhibiting phyllosilicate and a high proportion of Fe-Ni sulphide (Fig. 4c); and (ii) polycrystalline grains that occur in association with phyllosilicates, olivine grains and Fe-Ni sulphide inclusions (Fig. 7a \& 7b) inside flattened chondrules surrounded by a 318 fine-grained rim (hereafter FGR) (Fig. 7a \& 7b). T2a calcites show $\delta^{18} \mathrm{O}$ values between 17.2 and $22.5 \%$ (mean of $19 \%$, $\sigma=1.4 \%$ ),$\delta^{17} \mathrm{O}$ values between 6.2 and $8.8 \%$ (mean of $7.4 \%$, $\sigma$ $320=0.8 \%$ ) and heterogeneous $\Delta^{17} \mathrm{O}$ values, ranging from -3.5 to $-0.6 \%$ (mean of $-2.5 \%$, $\sigma=$

0.8\%o) (Fig. 5, Table 3). T2a calcites have variable C-isotopic compositions with $\delta^{13} \mathrm{C}$ values ranging from 30 to $70.7 \%$ (mean of $50.1 \%$, $\sigma=12.4 \%$ ) (Fig. 6, Table 3).

\subsubsection{Veins of calcite (blue triangles in figures)}

Calcite veins were only identified in lithology 1 (in the \#3, Fig. 2a) where they occur as polycrystalline grains of hundreds of micrometers in length and tens of micrometers in width (Fig. 4d). These veins are in direct contact with the matrix, are free of phyllosilicate, and can contain micrometer-sized Fe-Ni sulphide inclusions. Due to their irregular form and their low

330 thickness, only one successful O-isotopic measurement was carried out, revealing a $\delta^{18} \mathrm{O}$ 331 value of $16.9 \%$ o $(2 \sigma=0.6 \%)$, a $\delta^{17} \mathrm{O}$ value of $6.7 \%$ o $\left(2 \sigma=0.5 \%\right.$ ) and a $\Delta^{17} \mathrm{O}$ value of $-2 \%$ o 
$332(2 \sigma=0.7 \%)$. Unfortunately, no C-isotopic composition was successfully measured due to the 333 narrow width of the veins.

\subsection{Petrofabric analyses and aspect ratio of type I chondrules}

\subsubsection{Polished sections}

Lithology 1 in section \#3 contains several sets of $\sim 200-300 \mu \mathrm{m}$ fractures and $\sim 100-200$ $\mu \mathrm{m}$ veins of calcite orientated in planes near the petrofabric plane (i.e., within $30^{\circ}$ of the median azimuth), but also randomly oriented (Fig. 8a). Lithologies 1 and 3 in section \#3 define a strong petrofabric with $46 \%$ and $41 \%$, respectively, of the particle long-axes within $10^{\circ}$ of the median azimuth (Fig. 8a \& 8d). In contrast, lithologies 1 and 2 in section \#4 express a weak petrofabric with $26 \%$ and $21 \%$, respectively, of the particle long-axes within $10^{\circ}$ of the median azimuth (Fig. $\left.8 \mathbf{b} \& \mathbf{8 c}\right)$.

\subsubsection{Bulk Boriskino}

The orientation of the primary (R1) and tertiary (R3) axis lengths of 61 elliptic type I chondrules were plotted on stereonets in order to determine their degree of preferred alignment (Fig. 9a \& 9b). According to the method of Woodcock and Naylor (1983), the primary ellipsoid axis orientations of type I chondrules have a girdle distribution, with a shape parameter $(\mathrm{K})$ of 0.6 and a moderately weak foliation fabric strength, with a strength parameter (C) of 1.3 (Fig. 9a). The R3 ellipsoid axis orientations of type I chondrules have a cluster distribution, with a shape parameter $(\mathrm{K})$ of 1.9 and a moderately weak foliation fabric strength, with a strength parameter (C) of 1.3 (Fig. 9b). Both sample distributions are nonrandom at the $99 \%$ confidence level $\left(\mathrm{S}_{1} / \mathrm{S}_{3}=3.77\right.$ and $\mathrm{S}_{1} / \mathrm{S}_{3}=3.61$ for $\mathrm{R} 1$ and $\mathrm{R} 3$, respectively; Woodcock and Naylor, 1983). The diameters and volumes of best-fit chondrule 
358 ellipsoids are variable and range from $\sim 82$ to $531 \mu \mathrm{m}$ (primary axis length) and from 2 to 213

$359 \mu \mathrm{m}^{2}$, respectively (Table 2). Their aspect ratios are also heterogeneous, ranging from 1.11 to 3603.34 (mean value of $1.87, \sigma=0.46$, Table 2 ). 


\subsection{Oxygen isotopes and sequence of Ca-carbonate precipitation}

Boriskino contains two petrographic types of Ca-carbonate depending on the lithology considered: T1a Ca-carbonates (calcite and aragonite) and T2a calcites. T1a Cacarbonates are ${ }^{16} \mathrm{O}$-poor (mean $\delta^{18} \mathrm{O}$ and $\delta^{17} \mathrm{O}$ values of $33.9 \%$ and $16.7 \%$, respectively) with a mean and occur as small subhedral grains dispersed throughout the matrix of lithology 3 (Fig. 5, Table 2). In contrast, the T2a grains and calcite veins in lithologies 1 and 2 exhibit ${ }^{16} \mathrm{O}$-rich compositions compared to T1a grains (mean $\delta^{18} \mathrm{O}$ and $\delta^{17} \mathrm{O}$ values of 19\%o and 7.4\%o respectively, Fig. 5, Table 2). Some of the T2a calcites were observed in association with olivine grains and phyllosilicates located within chondrules that are surrounded by FGRs (Fig. 7a \& 7b). Based on these petrographic and isotopic features, it thus appears that Boriskino's Ca-carbonates define two distinct populations: a first population, made up of T1a calcite and aragonite, with mean $\delta^{18} \mathrm{O}$ and $\Delta^{17} \mathrm{O}$ values of $33.9 \%$ o $(\sigma=2.4 \%$ ) and $-1 \%$ o $(\sigma=0.4 \%$ ) respectively; and a second population, composed of T2a calcite and calcite veins, with $\delta^{18} \mathrm{O}$ and $\Delta^{17} \mathrm{O}$ values of $18.9 \%$ o $(\sigma=1.5 \%$ o $)$ and $2.5 \%$ o $(\sigma=0.8 \%$ ) respectively $($ Fig. 5b). Taken together, the O-isotopic compositions of Boriskino's Ca-carbonates define a trend with $\delta^{17} \mathrm{O}=0.62( \pm 0.05) \times \delta^{18} \mathrm{O}-4.3( \pm 1.3)$ $\left(2 \sigma, R^{2}=0.97 ;\right.$ MSWD $=11.6 ;$ Fig. 5a $)$ that does not fall on the mass-dependent fractionation line (TFL; Fig. 5a). This trend is closed, within errors, from those reported

(i) $\delta^{17} \mathrm{O}=0.62( \pm 0.09) \times \delta^{18} \mathrm{O}-4.1( \pm 2.8)\left(2 \sigma, \mathrm{R}^{2}=0.95, \mathrm{MSWD}=0.26\right.$, Tyra et al., 2012) 
(ii) $\delta^{17} \mathrm{O}=0.62( \pm 0.04) \times \delta^{18} \mathrm{O}-4.08( \pm 1.1)\left(2 \sigma, \mathrm{R}^{2}=0.99\right.$, MSWD $=1.7$,

$$
\delta^{17} \mathrm{O}=0.66( \pm 0.05) \times \delta^{18} \mathrm{O}-4.7( \pm 1.5)\left(2 \sigma, \mathrm{R}^{2}=0.87, \mathrm{MSWD}=3.3\right.
$$
Verdier-Paoletti et al., 2017a)

(iv) $\quad \delta^{17} \mathrm{O}=0.65( \pm 0.03) \times \delta^{18} \mathrm{O}-5.4( \pm 1.2)(2 \sigma$, Horstmann et al., 2014).

(v) $\quad \delta^{17} \mathrm{O}=0.70( \pm 0.03) \times \delta^{18} \mathrm{O}-5.65( \pm 1.25)(2 \sigma$, Lindgren et al., 2017)

392

The trend with a slope of $0.62 \pm 0.05$ defined by the Boriskino carbonates (and other CMs) cannot result from precipitation of the carbonates from a common fluid (i.e., with identical $\Delta^{17} \mathrm{O}$ values) along a temperature gradient, as this would have produced a slope of 0.52 (Fig. 10). Instead, it implies that the main process controlling the O-isotopic compositions of Ca-carbonates relies on variable degrees of isotopic exchanges between a ${ }^{16} \mathrm{O}$-poor fluid (i.e., a $\mathrm{CM}$ primordial water with $\delta^{18} \mathrm{O}=55 \pm 13 \%$ and $\delta^{17} \mathrm{O}=35 \pm 9 \%$; Fujiya, 2018) and ${ }^{16}$ O-rich anhydrous silicates (Clayton and Mayeda, 1999). In addition, the trend defined by the Boriskino Ca-Carbonates is, within error, parallel to the CM Water line (i.e., 0.69, Verdier-Paoletti et al., 2017a), and thus supports a mean carbonate precipitation temperature of $\approx 110^{\circ} \mathrm{C}$. However, this isotopic exchange model does not exclude the possibility that small temperature variations could have occurred during the course of alteration, generating a shift in carbonate O-isotopic compositions along a slope of 0.52 for a given degree of isotopic exchange (Fig. 10). In such a scenario, the ${ }^{16} \mathrm{O}$-poor population of Ca-carbonates would have precipitated early in Boriskino's alteration history, while the ${ }^{16} \mathrm{O}$ rich population would have formed later from more evolved fluids (Fujiya et al., 2016). These two stages of precipitation are also supported by (i) the identification of several aragonite grains in population 1 (Fig. 4a) - aragonite is expected to have predated calcite in some other least altered CM chondrites (Sofe, 2013; Lee et al., 2013, 2014; Lindgren et al., 2017; Vacher 
412 et al., 2017), and (ii) the occurrence of chondrule-hosted calcite in population 2 - calcites

413 which are frequently found in other highly altered CM chondrites and are inferred to have

414 formed under extensive episodes of aqueous alteration (Tyra et al., 2012; Lee et al., 2013,

415 2014; Fujiya et al., 2016). Determining the sequence of precipitation of Boriskino's Ca-

416 carbonates within each population is difficult to assess however. T1a calcites and aragonites

417 are commonly surrounded by Fe-, S- and Si-rich phyllosilicates (Fig. $4 a$ \& 4 b), suggesting

418 that the precipitation of $\mathrm{T} 1 \mathrm{a}$ Ca-carbonates predates the formation of phyllosilicates, as

419 already observed in other CM chondrites (Browning and Bourcier, 1998; Lee et al., 2013;

420 Fujiya et al., 2016; Pignatelli et al., 2017, 2018; Vacher et al., 2017). Nevertheless, our

421 isotopic and petrographic results do not allow us to discriminate the formation sequence of

422 T1a calcite and aragonite (Fig. 5 \& 6; Table 3). In population 2, the T2a calcites were

423 identified in lithologies 1 and 2. These lithologies exhibit high proportions of phyllosilicates

424 compared to lithology 3 (Table 1) and show systematic evidence of mafic silicate

425 replacement by serpentine (Fig. 3a, 3b and 7). To the contrary, T2a calcites and calcite veins

426 have not been affected by phyllosilicate replacement, as demonstrated by the absence of

427 serpentine rims around these grains (Fig. 4c, 4d and 7). Taken together, these results indicate

428 that T2a and veins of calcite precipitated after the formation of phyllosilicates. However,

429 based on our results, no order of precipitation for T2a grains and calcite veins can be inferred.

430 

that lithologies 1 (section \#3) and 3 define a strong petrofabric whereas lithologies 1 (section \#4) and 2 exhibit a weak petrofabric (Fig. 8). Conceptually, it might appear surprising that, from one section to another, the level of aligned particles can show dramatically different values within a given lithology. However, similar results have already been reported from SEM-BSE images of several faces of a 3D block of Murchison (Lindgren et al., 2015). Significant differences in the level of chondrule alignment were reported, based on the orientation of the sides of the block $\left(20 \%, 40 \%\right.$ and $50 \%$ of chondrule long axes within $10^{\circ}$ of

442 the median azimuth for $+z,-y$ and $+x$ sides, respectively; Lindgren et al., 2015). Because the 443 Boriskino lithology 1 occurs in two different sections, clasts from lithology 1 could show 444 different spatial orientations, depending on their location on the sample or the orientation of 445 the section cutting and thus, display varying petrographic intensities. Nevertheless, the 446 strongest fabric value measured in lithology 1 (i.e., 46\%, Fig. 8a) is probably the one with the 447 closest value to the actual maximum. Consequently, we assume that lithology 1 defines a 448 strong petrofarbic despite variations of its particle orientations.

The 3D bulk analyses of type 1 chondrules revealed that Boriskino exhibits a moderately weak foliation fabric $(\mathrm{C}=1.3)$ and a high degree of chondrule flattening $(1.87 \pm 0.46)$. This result is consistent with the two XCT studies of Murchison that showed moderately weak 452 petrofabric $(\mathrm{R} 1)$ and high aspect ratio $(\mathrm{C}=1.46$, aspect ratio $=1.75 \pm 0.39$, Lindgren et al., 453 2015; $\mathrm{C}=1.02$, aspect ratio $=1.54 \pm 0.22$, Hanna et al., 2015). A large number of studies 454 have reported chondrule flattening and/or occurrence of petrofabrics in (i) ordinary chondrites 455 (hereafter OCs) (Cain et al., 1986; Stöffler et al., 1991; Scott et al., 1992; Gattacceca et al., 456 2005; Rubin and Swindle, 2011), (ii) CV chondrites (Nakamura et al., 2000; Watt et al., 2006; 
Rubin, 2012) (iii) fined-grained micrometeorites (hereafter FgMMs) (Suttle et al., 2017) and (iv) CM chondrites (Tomeoka et al., 1999; Rubin, 2012; Lindgren et al., 2015; Hanna et al., 2015). Chondrule flattening or petrofabrics are generally interpreted to be the result of impact-induced preferential orientations (Sneyd et al., 1988; Stöffler et al., 1991; Scott et al., 1992; Tomeoka et al., 1999; Nakamura et al., 2000; Gattacceca et al., 2005; Rubin and Swindel, 2011; Rubin, 2012; Lindgren et al., 2015; Hanna et al., 2015; Forman et al., 2016; Suttle et al., 2017) rather than a consequence of lithostatic compaction (Martin and Mills, 1980; Fujimara et al., 1983; Cain et al., 1986; Zolensky et al., 1997; Lee and Ellen, 2008).

Shock metamorphism evidence in OCs was used to propose a comprehensive petrographic classification of their degree of shock (S1 to S6, Stöffler et al. 1991). Based on shock classification, Gattacceca et al. (2005) demonstrated a relationship between the anisotropy of magnetic susceptibility (AMS) and the silicates's shock features in OCs. Collisional evidence was also reported in $\mathrm{CV}$ chondrites with (i) the occurrence of S3-S4 petrofabrics (Rubin, 2012) and shock features in olivine and pyroxene grains (Nakamura et al., 1992) and (ii) a strong anticorrelation between their porosity content and their level of shock stage (Gattacceca et al., 2005). More recently, the study of a large number of micrometeorites showed that around $40-80 \%$ of FgMMs display petrofabrics, biaxial fabrics and brittle deformation features, indicating that at least some fabrics are impacted at shock pressures > 0.08 GPa. (Suttle et al., 2017). Based on oxygen isotopic compositions as well as textural and geochemistry features, it appears that micrometeorites are related to CM chondrites (Kurat et al., 1994; Brownlee et al., 1997; Genge et al., 1997; Suavet et al., 2010; Gounelle et al., 2005). Although CM chondrites contain shock compaction features similar to FgMMs, (Lindgren et al., 2011; 2015; Rubin, 2012; Hanna et al., 2015), they do not contain high grade shock features (i.e., > S1-S2; Scott et al., 1992). This contradiction might be related to the capability of porous CMs to absorb and dissipate impact energy due to collapse of the pore 
482

483

484

485

486

487

488

489

490

491

492

493

494

495

496

497

498

499

500

501

502

503

504

505

506

space (Suttle et al., 2017). A such process has been demonstrated in Murchison with (i) the observation of squeezed chondrules resulting from a component of noncoaxial shear induced by impact and (ii) the loss of $\approx 10-31 \%$ of chondrule bulk porosity after shock compactions (Hanna et al., 2015). In Boriskino, we also observed squeezed chondrules within lithology 1 (\#4, Fig. 7c). Other evidence of impact-induced CM petrofabrics has been highlighted in different studies, including the regolith-brecciated nature of CMs (Metzler et al., 1992; Rubin, 2012) and multiple episodes of deformation recorded by a calcite vein in the LON $94101 \mathrm{CM}$ (Lindgren et al., 2011).

Shock recovery-experiments were performed on CM2 and CV3 chondrites and successfully reproduced the flattened shapes of chondrules and their petrofabrics (Nakamura et al., 1995; 2000; Tomeoka et al., 1999). These experiments were carried out at various peak pressure intensities on Murchison (4-49 GPa) and Allende (11-21GPa) and demonstrated a good correspondence between the aspect ratio of $\mathrm{CM}$ and $\mathrm{CV}$ chondrules and impact pressures (Fig. 11). From these experimental correlations, it is possible to quantitatively estimate the intensity of a single impact that induced the chondrule aspect ratio in Boriskino. The mean XCT chondrule aspect ratio of $1.87 \pm 0.46$ (Table 2) corresponds to impacts with intensities ranging from 18 to $>30 \mathrm{GPa}$ and 8-31 GPa, taking into account the experiment results obtained on Murchison and Allende, respectively (Fig. 11; Tomeoka et al., 1999; Nakamura et al., 2000). They are consistent with those determined in the CMs MET 01072, Murchison and LAP 031166 (Lindgren et al., 2015; Hanna et al., 2015) (Fig. 11). Taken together, our results suggest that some of the CMs probably underwent high intensity impacts. Nevertheless, shock pressure estimations should be treated with caution as they represent the effect of only a single impact on the parent body. Because Boriskino represents the final assemblage of several clasts of different lithology and deformation degree, it seems unlikely that each clast experienced the same collisional history. In addition, the pressure estimates 
507 determined from shock-recovery experiments on Murchison suggest a high intensity of shock 508 pressure, with pressures that may have exceeded $30 \mathrm{GPa}$ and which should have induced 509 melting of the matrix and chondrules (Tomeoka et al., 1999). However, no evidence for 510 melting has been observed in Boriskino.

511 To summarize, there are several lines of evidence for shock features in Boriskino, 512 including (i) a strong 2D petrofabric in different lithologies, (ii) flattened chondrules, (iii) 513 calcite veins and fractures subparallel to the petrofabric, (iv) squeezed chondrules, and (v) 514 millimeter clasts of various petrographies in direct contact with each other. Based on these 515 observations, we suggest that some of the clasts that make up the Boriskino meteorite (i.e., 516 clasts composed of lithologies 1 and 2) were subjected to high intensity impact(s) (i.e., 10-30 $517 \mathrm{GPa})$ that produced petrofabrics, chondrule flattening, and fractures. 
Understanding the relative timing between deformation and aqueous alteration in chondrites is crucial, because it can provide constraints on the conditions of parent-body alteration (Brearley, 2006). It is commonly accepted that aqueous alteration of CM chondrites

524 took place on their parent body(-ies) due to heat released by the decay of ${ }^{26} \mathrm{Al}$ (Dufresne and 525 Anders, 1962; Zolensky et al., 1997). Shock compaction has also been advanced as a principal 526 alteration process in CM chondrites (Greenwood et al., 1994; Rubin, 2012; Lindgren et al., 527 2015; Hanna et al., 2015). Based on a strong correlation between the degree of alteration and the intensity of impact compaction (Fig. 12), Rubin (2012) proposed that random collisions may induce the formation of fractures and favor the mobilization of liquid water by 530 dehydration of phyllosilicates or the melting of ice. This is also supported by the occurrence 531 of dolomite veins with similar orientation to their respective petrofabrics in the highly altered 532 CM2 QUE 93005 and CM1 SCO 06043 (Lindgren et al., 2015). Other reported petrographic evidence for impact-induced alteration includes (i) serpentine veins parallel to the foliation 534 fabric in Murchison (Hanna et al., 2015) and (ii) millimeter lenses rich in phyllosilicates, Ni535 bearing sulfide and Ca-phosphate grains subparallel to fractures and elongated chondrules in 536 the CM1 MET 01070 (Rubin et al., 2007; Lindgren et al., 2012). The latter suggests the 537 precipitation of secondary minerals from transported fluid in preexisting fractures (Rubin, 538 2012). In Boriskino, lithologies 1 and 2 exhibit petrographic features consistent with a high 539 degree of alteration (i.e., petrologic subtype expected to be 2.1) as demonstrated by the 540 (i) partial alteration of mafic silicates into chondrules (Fig. 3a \& 3b), (ii) low metallic Fe-Ni 541 content $\left(\leq 0.05\right.$ vol.\%, Table 1) and (iii) occurrence of ${ }^{16} \mathrm{O}$-rich T2a grains (Fig. 5a, Rubin, 542 2012). Lithologies 1 and 2 also define strong and weak petrofabrics (i.e., 26 and $46 \%$ for 543 lithology 1, respectively, Fig. 8a and b) that probably result from different spatial 
544 orientations (also expected for the lithology 2 due to its weak petrofabric) and/or separate

545 section's positions on the cutting plane. However, considering the strongest fabric measured 546 as the closest value to the actual maximum (i.e., 41\%, Fig. 8a), the relationship between 547 degree of alteration $v s$ strength of the petrofabric for the lithology 1 is consistent with the 548 correlation defined by Rubin (2012) and thus favour models of impact-induced alteration 549 (Fig. 12). In addition, the occurrence of large calcite veins subparallel to the petrofabric (Fig 550 4a and 8a) and the replacement of primary elongated chondrules by T2a calcite (Fig. 7a \& b) 551 also support this type of alteration process. For the lithology 2, the lack of calcite vein and the 552 weak intensity of its fabric are more problematic, but according to petrographic observations 553 (i.e., T2a grains and replacement of elongated chondrules), we assumed similar alteration 554 process than for the lithology 1.

555 In contrast, lithology 3 presents characteristics consistent with a lower degree of alteration 556 (i.e., presumed to be petrologic subtype 2.5-2.6; Rubin, 2015), due to: (i) unaltered mafic 557 silicates into chondrules (Fig. 3c), (ii) a significant abundance of Fe-Ni metal beads (i.e., $~ 0.5$ 558 vol.\%, Table 1) and (iii) the presence of ${ }^{16} \mathrm{O}$-poor T1a calcite and aragonite. Furthermore, 559 lithology 3 does not show any petrographic features characteristics of impact-induced fluid 560 circulation within fractures (e.g., vein of carbonate). Instead, this lithology appears to contain 561 undistorted Ca-carbonates wrapped by phyllosilicates (Fig. 13a), stretched clumps of 562 phyllosilicates, and elongate sulphide grains parallel to the petrofabric (Fig. 13b). These 563 observations suggest that secondary minerals precipitated before the formation of the 564 petrofabric and that aqueous alteration predates the deformation. Furthermore, by reporting 565 the petrofabric intensity (i.e., 41\%) as function of the expected CM subtype of the lithology 3 566 (Fig. 12), it is observed that the percentage of particles with long axes within $10^{\circ}$ is to high 567 compared to the predicted value from the correlation of Rubin (2012) (i.e., $\approx 15 \%$, Fig. 12). 568 The strong petrofabric observed in the lithology 3 probably results on later episodes of 
deformation that have not affected alteration but only increased the preferential orientation of 570 particles in the lithology 3 (Fig. 12).

571 Our results demonstrate that Boriskino is a clastic polymict breccia, composed of various 572 lithologies, in direct contact with each other, that display different degrees of alteration and 573 deformation histories. Based on our petrographic and isotopic results, we propose a 574 deformation and alteration history for Boriskino based on a single CM parent body, where the 575 different clasts of the breccia chondrite come from different regions of the asteroid (Fig. 14a) 576 (Scott and Taylor, 1983; Lindgren et al., 2013). At time $t_{1}$ in our scenario, aqueous alteration 577 processes were initiated through the melting of ice induced by ${ }^{26} \mathrm{Al}$ decay within the parent 578 body (Fig. 14a). Hence, the ${ }^{16} \mathrm{O}$-poor primitive fluid interacts with the ${ }^{16} \mathrm{O}$-rich anhydrous 579 components of the parent body to precipitate isolated aragonite and calcite grains in the 580 matrix as observed in lithology 3. Then, as alteration progresses, the chemical composition of 581 the fluid changes, stopping the precipitation of $\mathrm{T} 1$ carbonate and initiating phyllosilicate 582 formation. We do not exclude the possibility that these events occurred in lithologies 1 and 2 583 as well, but to date, no evidence for these events has been observed. Next, at time $t_{2}$, one or 584 several high intensity impacts induced the formation of fractures and petrofabrics and the 585 stretching of chondrules, principally in lithologies 1 and 2 due to their location close to the 586 impact zone (Fig. 14b). Subsequently, at time $t_{3}$, the establishment of cracks and fractures 587 favored the circulation of evolved ${ }^{16} \mathrm{O}$-rich fluids within the parent body (Fig. 14c). This late 588 fluid flow would have allowed the formation of phyllosilicate and T2 carbonate in chondrules 589 and the precipitation of veins of calcite in fractures (Fig. 14c). Finally, at time $t_{4}$, a new 590 episode of low intensity impact(s) generated the release of all Boriskino's clasts from their 591 initial locations, making possible the mixing of the different altered lithologies together to 592 form the clastic polymict breccia Boriskino (Fig. 14d). 
The in situ $\delta^{13} \mathrm{C}-\delta^{18} \mathrm{O}$ compositions of Ca-carbonates in Boriskino are consistent with those reported in other CM carbonates (Fig. 15; Fujiya et al., 2015, 2016; Tyra et al., 2016; Telus et al., 2017; Vacher et al., 2017). Our results show that Boriskino's Ca-carbonates exhibit two different populations with distinct $\delta^{18} \mathrm{O}$ values and significant variations in $\delta^{13} \mathrm{C}$ values (i.e., $\delta^{18} \mathrm{O} \approx 35 \%$ o, $\delta^{13} \mathrm{C} \approx 20-90 \%$ and $\delta^{18} \mathrm{O} \approx 20 \%$, $\delta^{13} \mathrm{C} \approx 30-70 \%$ for T1a and T2a, respectively). Furthermore, these Ca-carbonates do not show positive or negative $\delta^{13} \mathrm{C}-\delta^{18} \mathrm{O}$ 602 correlations, whether for all the dataset or within each population (Fig. 15). Because the fractionation factor of $\mathrm{C}$ isotopes between calcite and $\mathrm{HCO}_{3}{ }^{-}$in the fluid is small at $0-300^{\circ} \mathrm{C}$ (i.e., $1000 \ln \alpha_{\text {calcite-HCO3- }} \approx 1-2 \%$; Deines et al., 1974; Luo and Wang, 2009), the $\delta^{13} \mathrm{C}$ values of Ca-carbonates are useful for (i) tracking the source of carbon involved in their precipitation (Grady et al., 1988; Alexander et al., 2015; Fujiya et al., 2015; Vacher et al., 2017) and (ii) identifying fractionation mechanisms, such as equilibrium or kinetic isotope fractionation (e.g., production of $\mathrm{CH}_{4}$ or loss of $\mathrm{C}$-bearing gas from the fluid during serpentinization or degassing events, respectively; Guo and Eiler, 2007; Fujiya et al., 2016; Telus et al., 2017). The C and O-isotopic compositions of Boriskino's Ca-carbonates can be explained in numerous ways. Their $\delta^{13} \mathrm{C}-\delta^{18} \mathrm{O}$ values can be reproduced by the equilibration of a $\mathrm{CO}$ gas $\left(\delta^{13} \mathrm{C}_{\mathrm{CO}}=-33 \%\right.$ ) with different mole fraction of $\mathrm{CO}_{2}$ in a ${ }^{16} \mathrm{O}$-rich aqueous fluid $\left(\delta^{18} \mathrm{O}=5 \%\right.$ ) at low temperature $\left(\approx 0-30^{\circ} \mathrm{C}\right.$ and $\approx 80-120^{\circ} \mathrm{C}$ for $\mathrm{T} 1 \mathrm{a}$ and $\mathrm{T} 2 \mathrm{a}$, respectively; Alexander et al., 2015) (Fig. 16a). They can also be the result from different fluids derived from variable Oisotopic equilibration and contributions of different ${ }^{12} \mathrm{C}$ - and ${ }^{13} \mathrm{C}$-rich water-soluble organic 616 compounds (SOM) which demonstrated similar range of $\delta^{13} \mathrm{C}$ values (i.e., -10 to $60 \%$, Fig. 617 16a, Vacher et al., 2017). However, these two models consider a closed-system alteration 618 without the escape of C-bearing species. As demonstrated by our petrographic results, T2a 
619 calcites occur in lithologies that have probably undergone multiple episodes of shock 620 compactions causing the formation of cracks and fractures. Under such conditions, the closed621 system is merely an approximation; highly diffusive gas such as C-bearing molecules (e.g., $622 \mathrm{CO}_{2}$ or $\mathrm{CH}_{4}$ ) likely escaped rapidly from the shocked regions. Such a process has been put 623 forward to explain the occurrence of two distinct isotopic groups of calcite in CM MET 62401070 , characterized by (i) high $\delta^{18} \mathrm{O}$ and variable $\delta^{13} \mathrm{C}$ compositions, and (ii) low $\delta^{18} \mathrm{O}$ and 625 high $\delta^{13} \mathrm{C}$ values (Fig. 15; Telus et al., 2017). The authors interpreted this shift in $\delta^{13} \mathrm{C}$ values 626 as the result of a venting event, in agreement with the petrographic evidence of fluid flow in 627 MET 01070 (Rubin et al., 2007). Based on a negative $\delta^{13} \mathrm{C}-\delta^{18} \mathrm{O}$ correlation observed in CM 628 carbonates, it has been also proposed that carbonate precipitation was accompanied by the 629 production of ${ }^{13} \mathrm{C}$-depleted $\mathrm{CH}_{4}$ and its escape from the $\mathrm{CM}$ parent body (Guo and Eiler, 630 2007). However, as highlight in terrestrial environment, abiotic methane is not produced 631 directly by serpentinization, but through the reduction of various $\mathrm{C}$-bearing (e.g., $\mathrm{CO}, \mathrm{CO}_{2}$ or $632 \mathrm{HCO}_{3}^{-}$) species by $\mathrm{H}_{2}$ during Fischer Tropsch type (FTT) or Sabatier processes 633 (Proskurowski, 2010; Etiope and Sherwood Lollar, 2013):

$634 \mathrm{HCO}_{3}^{-}+4 \mathrm{H}_{2}=\mathrm{CH}_{4}+\mathrm{H}_{2} \mathrm{O}+\mathrm{OH}^{-} \quad$ (in aqueous phase; Horita and Berndt, 1999)

635 In $\mathrm{CM}$ chondrites, $\mathrm{H}_{2}$ is believed to form during the serpentinization of olivine/pyroxene 636 minerals (Pignatelli et al., 2017) and/or the corrosion of kamacite grains (Palmer and Lauretta, 637 2011). Reaction kinetics of FTT or Sabatier processes are theoretically much efficient at high 638 temperature than at lower temperatures $\left(<100^{\circ} \mathrm{C}\right)$. Nevertheless, $\mathrm{CH}_{4}$ production could be 639 significant at low temperature due to the action of different catalyses, such as chromite, 640 magnetite or Fe-Ni alloys (Horita and Berndt, 1999; Foustoukos and Seyfried, 2004) which 641 occur in CM chondrites (Brearley, 2006; Hewins et al., 2014).

642 Because T2a calcites have precipitated after the formation of fractures and petrofabrics 643 in the lithologies 1 and 2, we propose that the variability in the $\delta^{13} \mathrm{C}$ values can reflects the 
644 release of ${ }^{13} \mathrm{C}$-depleted $\mathrm{CH}_{4}$ produced by FFT or Sabatier reactions through cracks induced by 645 high intensity impact(s). We also considered that escape of $\mathrm{CH}_{4}$ has been limited for T1a 646 carbonates because they probably formed prior serpentine (Lee et al., 2014; Vacher et al., 647 2017) and thus, they are no include in the model. Furthermore, escape of $\mathrm{CO}_{2}$ is not taking 648 account in this model, because carbon dioxide is preferentially release in acid environment 649 (e.g., at $\mathrm{pH}=4-6$ in terrestrial evaporating Dead Sea brines, Stiller et al., 1985) whereas 650 alteration in CM chondrites appears to occur in alkaline environment (Palmer and Lauretta, 651 2011; Zolotov, 2014; Pignatelli et al., 2016; 2017). Assuming an aqueous fluid with dissolved $652 \mathrm{HCO}_{3}{ }^{-}, \mathrm{CH}_{4}$ and $\mathrm{CO}_{2}$ at isotopic equilibrium in an open system model, the amount of can be 653 calculated using a Rayleigh-type isotopic equation:

$$
R_{\mathrm{HCO}_{3}^{-}}=R_{\mathrm{HCO}_{3}^{-}} \times f^{\left(\mathrm{a}_{\left.\left(\mathrm{HCO}_{3}^{-} / \mathrm{CH}_{4}\right)^{-1}\right)}\right.}
$$

655 656

where $R_{\mathrm{HCO}_{3}^{-}}$is the isotopic ratio of the $\mathrm{HCO}_{3}{ }^{-}$after a certain amount of Rayleigh distillation, $R_{\mathrm{HCO}_{3}^{-}}$is the initial isotopic ratio of $\mathrm{HCO}_{3}^{-}, f$ is the fraction of phase $\mathrm{HCO}_{3}^{-}$remaining, and $\mathrm{a}_{\mathrm{HCO}_{3}^{-} / \mathrm{CH}_{4}}$ is the equilibrium fractionation factor between $\mathrm{HCO}_{3}{ }^{-}$and $\mathrm{CH}_{4}$. By incorporating the delta notation (i.e., $\left.\delta^{13} \mathrm{C}\right)$ instead of the isotopic ratio $\left({ }^{13} \mathrm{C} /{ }^{12} \mathrm{C}\right)$ in Eqn. (1), we obtain the following equation:

$$
\delta^{13} C_{\mathrm{HCO}_{\overline{3}}^{-}}=\left[\left(1000+\delta^{13} C_{\mathrm{HCO}_{\overline{3}}}\right) \times f^{\left(\mathrm{a}_{\left.\left(\mathrm{HCO}_{3}^{-} / \mathrm{CH}_{4}\right)^{-1}\right)}\right.}\right]-1000
$$

Hence, the estimates of the C-isotopic compositions of the fluid (i.e., the $\delta^{13} C_{\mathrm{HCO}_{\overline{3}}}$ values) for different amounts of $\mathrm{HCO}_{3}{ }^{-}$escape are dependent on (i) the initial $\mathrm{C}$-isotopic composition of the fluid (i.e., the $\delta^{13} C_{\mathrm{HCO}_{\overline{3}_{0}}}$ value) and (ii) the equilibrium fractionation factor between $\mathrm{HCO}_{3}{ }^{-}$and $\mathrm{CH}_{4}$, which is a direct function of the temperature. This calculation is also linked to a fundamental assumption, that the oxygen isotopes of the water constitute an infinite reservoir and thus, the O-isotopic composition of the fluid is not affected by the Rayleigh distillation. 
669 similar trends (except for the $\delta^{13} \mathrm{C}-\delta^{18} \mathrm{O}$ values of MET 01070) with their C-isotopic 670 compositions converging toward a low range of $\delta^{13} \mathrm{C}$ values for a high degree of O-isotopic 671 equilibration (i.e., $\delta^{13} \mathrm{C}_{\text {calcite }} \approx 20-30 \%$ ) (Fig. 15). Furthermore, by including the $\delta^{13} \mathrm{C}-\delta^{18} \mathrm{O}$ 672 values of the type 1 and type 2 calcites from the CM2 Nogoya (Fujiya et al., 2016), these two 673 groups exhibit constant $\delta^{13} \mathrm{C}$ values for different $\mathrm{O}$-isotopic compositions (excluding 2 points 674 from the type 2$)$ at $\delta^{13} \mathrm{C}_{\text {calcite }} \approx 30 \%$ o $\left(\sigma \approx 4 \%\right.$ ) (Fig. 16b). As the lowest $\delta^{13} \mathrm{C}$ value of the T2a 675 calcite in Boriskino displays similar C-isotopic composition to the Nogoya calcites and the 676 two $\mathrm{CM}$ tendencies (i.e., $\delta^{13} \mathrm{C}_{\text {calcite }}=30 \%$ for the $\mathrm{CC} 9$ grain), we assume that this value 677 represents the initial $\delta^{13} C_{\mathrm{HCO}_{\overline{3}_{0}}}$ of the fluid. Interestingly, this value is consistent with the 678 range of C-isotopic values of the SOM reported by Sephton and Botta (2005) in Murchison. 679 Thus, by combining the carbon equilibrium fractionation factors of $\mathrm{HCO}_{3}{ }^{-} / \mathrm{CO}_{2}\left(5-125^{\circ} \mathrm{C}\right.$, 680 Mook et al., 1974) and $\mathrm{CO}_{2} / \mathrm{CH}_{4}\left(0-700^{\circ} \mathrm{C}\right.$, Bottinga, 1969), we can determine the 681 equilibrium fractionation factor of $\mathrm{HCO}_{3}{ }^{-} / \mathrm{CH}_{4}$ for a given temperature. Assuming a mean 682 temperature of precipitation for $\mathrm{T} 2 \mathrm{a}$ calcites of $110^{\circ} \mathrm{C}$, the equilibrium fractionation factor of $683 \mathrm{HCO}_{3}{ }^{-} / \mathrm{CH}_{4}$ is 0.9535 at $110^{\circ} \mathrm{C}\left(1000 \ln \alpha_{\mathrm{CH} 4-\mathrm{HCO} 3-}=-47.6 \%\right)$. Hence, the observed $\delta^{13} \mathrm{C}$ 684 variabilities in T2a calcite in Boriskino (i.e., $\delta^{13} \mathrm{C}_{\text {calcite }}=38-65 \%$, Table 3 ) can be explained 685 by a loss of $\approx 15-50 \%$ of dissolved carbon from the fluid into $\mathrm{CH}_{4}$. We note that this estimate 686 is largely temperature dependent, and different results will be found at other temperatures 687 (Fujiya et al., 2016).

\section{CONCLUSIONS}


693 alteration history and collisional activity that took place on their parent body. From a

694 petrographic and isotopic survey of Ca-carbonates in the clastic breccia CM2 Boriskino, we 695 have investigated and traced the relative timings of deformation and aqueous alteration of the 696 CM parent body. The principal results of this paper are:

697 (1) Boriskino is composed of millimeter clasts, in direct contact with each other, that display various lithologies characterized by different degrees of alteration and deformation histories.

(2) The least altered lithology (lithology 3) contains Type 1a Ca-carbonates that are surrounded by phyllosilicates. Type 1a Ca-carbonates are ${ }^{16} \mathrm{O}$-poor and precipitated early in Boriskino's alteration history. This is interpreted as the result of isotopic exchange between a ${ }^{16} \mathrm{O}$-poor fluid and ${ }^{16} \mathrm{O}$-rich anhydrous silicates in a closed-system model. Petrographic observations suggest that secondary minerals formed before the establishment of the petrofabric, and thus that alteration predated the deformation.

(3) The more altered lithologies (lithologies 1 \& 2) are composed of ${ }^{16} \mathrm{O}$-rich Type 2a Ca-

(4) Based on strong evidence of shock features in Boriskino, we propose that some of the clasts that make up the Boriskino meteorite were subjected to high pressure impact(s) (i.e., 10-30 GPa) that generated strong petrofabrics, chondrule flattening and fractures.

(5) Taking all our results together, we propose a reconstruction of the deformation and alteration history of Boriskino in which the different lithologies are explained by their separate positions into the $\mathrm{CM}$ parent body. Assuming multiple shock compaction events, the occurrence of a strong petrofabric, calcite veins and elongated chondrules in the more altered lithologies could be explained by their location close to the impact 
zone, promoting a late circulation of fluid flow into fractures.

(6) Based on the C-isotopic composition of Boriskino Ca-carbonates, we propose that the formation of T2a calcite probably can took place in an open system environment with a loss of ${ }^{13} \mathrm{C}$-depleted $\mathrm{CH}_{4}$ produced from the reduction of C-bearing species by $\mathrm{H}_{2}$ released during serpentinization or kamacite corrosion (Guo and Eiler, 2007). Considering a mean precipitation temperature of Ca-carbonates of $110^{\circ} \mathrm{C}$, an escape of $\approx 15-50 \%$ of dissolved carbon into $\mathrm{CH}_{4}$ by Rayleigh distillation is able to reproduce the range of $\mathrm{C}$-isotopic compositions observed in $\mathrm{T} 2 \mathrm{a}$ calcites.

726 


\section{ACKNOWLEDGMENTS}

728

729

We are very grateful to Nordine Bouden for his helpful assistance with the carbon and

730 oxygen isotope measurements, to Patricia Wils and the AST-RX UMS 2700 MNHN technical

731 facilities for their technical support with the XCT analyses and to Marie-Camille Caumon for

732 her assistance with the Raman analyses. We also thank the Muséum National d'Histoire

733 Naturelle de Paris (MNHN) for the loan of the Boriskino samples. This work was funded by

734 l'Agence Nationale de la Recherche through grant ANR-14-CE33-0002-01 SAPINS (PI Yves

735 Marrocchi). This is a CRPG contribution\#2568 And SAPINS contribution \#11.

736 
Alexander C. M. O., Bowden R., Fogel M. L. and Howard K. T. (2015) Carbonate abundances and isotopic compositions in chondrites. Meteorit. Planet. Sci. 50, 810833.

Benedix G., Leshin L., Farquhar J., Jackson T. and Thiemens M. (2003) Carbonates in CM2 chondrites: constraints on alteration conditions from oxygen isotopic compositions and petrographic observations. Geochim. Cosmochim. Acta 67, 1577-1588.

Bischoff A., Ebert S., Metzler K. and Lentfort S. (2017) Breccia classification of CM chondrites. In 80th Annual Meeting of the Meteoritical Society. \#6089 (abstr.).

Bottinga Y. (1969) Calculated fractionation factors for carbon and hydrogen isotope exchange in the system calcite-carbon dioxide-graphite-methane-hydrogen-water vapor. Geochim. Cosmochim. Acta 33, 49-64.

Brearley A. J. (2006) The action of water. Meteor. Early Sol. Syst. II 943, 587-624.

Browning L. B. and Bourcier W. L. (1998) On the Origin of Rim Textures Surrounding Carbonate Grains in CM Matrices. In Lunar and Planetary Science Conference Lunar and Planetary Inst. Technical Report.

Brownlee D. E., Bates B., and Schram L. (1997) The elemental composition of stony cosmic spherules. Meteorit. Planet. Sci., 32, 157-175.

Bunch T. E. and Chang S. (1980) Carbonaceous chondrites-II. Carbonaceous chondrite phyllosilicates and light element geochemistry as indicators of parent body processes and surface conditions. Geochim. Cosmochim. Acta 44, 1543-1577.

Cain P. M., McSween H. Y. and Woodward N. B. (1986) Structural deformation of the Leoville chondrite. Earth Planet. Sci. Lett. 77, 165-175.

Clark B. E., Ziffer J., Nesvorny D., Campins H., Rivkin A. S., Hiroi T., Barucci M. A., Fulchignoni M., Binzel R. P., Fornasier S., DeMeo F., Ockert-Bell M. E., Licandro J. and Mothé-Diniz T. (2010) Spectroscopy of B-type asteroids: Subgroups and meteorite analogs. J. Geophys. Res. Planets 115, 1-22.

Clayton R. N. and Mayeda T. K. (1999) Oxygen isotope studies of carbonaceous chondrites. Geochim. Cosmochim. Acta 63, 2089-2104.

Clayton R. N. and Mayeda T. K. (1984) The oxygen isotope record in Murchison and other carbonaceous chondrites. Earth Planet. Sci. Lett. 67, 151-161.

Cloutis E. A., Hiroi T., Gaffey M. J., Alexander C. M. O. and Mann P. (2011) Spectral reflectance properties of carbonaceous chondrites: 1. CI chondrites. Icarus 212, 180209.

DeCarli P. S., Bowden E. and Seaman L. (2001) Shock-induced compaction and porosity in meteorites. In 64th Annual Meeting of the Meteoritical Society. \#5171 (abstr.). 
De Leuw S., Rubin A. E. and Wasson J. T. (2010) Carbonates in CM chondrites: Complex formational histories and comparison to carbonates in CI chondrites: Carbonates in CM chondrites. Meteorit. Planet. Sci. 45, 513-530.

Deines P., Langmuir D. and Harmon R. S. (1974) Stable carbon isotope ratios and the existence of a gas phase in the evolution of carbonate ground waters. Geochim. Cosmochim. Acta 38, 1147-1164.

Dufresne E. R. and Anders E. (1962) On the chemical evolution of the carbonaceous chondrites. Geochim. Cosmochim. Acta 26, 1085-1114.

Etiope G. and Sherwood Lollar B. (2013). Abiotic Methane On Earth. Reviews of Geophysics, 51(2012), 276-299.

Forman L. V., Bland P. A., Timms N. E., Collins G. S., Davison T. M., Ciesla F. J., Benedix G. K., Daly L., Trimby P. W., Yang L. and Ringer S. P. (2016) Hidden secrets of deformation: Impact-induced compaction within a CV chondrite. Earth Planet. Sci. Lett. 452, 133-145.

Foustoukos D. I. and Seyfried W. E. (2004) Hydrocarbons in hydrothermal vent fluids: the role of chromium-bearing catalysts. Science 304, 1002-1005.

Fujimura A., Kato M. and Kumazawa M. (1983) Preferred orientation of phyllosilicate [001] in matrix of Murchison meteorite and possible mechanisms of generating the oriented texture in chondrites. Earth Planet. Sci. Lett. 66, 25-32.

Fujiya W. (2018) Oxygen isotopic ratios of primordial water in carbonaceous chondrites. Earth Planet. Sci. Lett. 481, 264-272.

Fujiya W., Sugiura N., Marrocchi Y., Takahata N., Hoppe P., Shirai K., Sano Y. and Hiyagon H. (2015) Comprehensive study of carbon and oxygen isotopic compositions, trace element abundances, and cathodoluminescence intensities of calcite in the Murchison CM chondrite. Geochim. Cosmochim. Acta 161, 101-117.

Fujiya W., Fukuda K., Koike M., Ishida A. and Sano YA. (2016) Oxygen and carbon isotopic ratios of carbonates in the Nogoya CM chondrite. Lunar Planet. Sci. 47. Lunar Planet. Inst., Houston. \#1712 (abstr.).

Gattacceca J., Rochette P., Denise M., Consolmagno G. and Folco L. (2005) An impact origin for the foliation of chondrites. Earth Planet. Sci. Lett. 234, 351-368.

Genge M. J., Grady M. M. and Hutchison R. (1997) The textures and compositions of finegrained Antarctic micrometeorites: Implications for comparisons with meteorites. Geochim. Cosmochim. Acta 61, 5149-5162.

Gounelle M., Engrand C., Maurette M., Kurat G., McKeegan K. D. and Brandstätter F. (2005) Small Antarctic micrometeorites: A mineralogical and in situ oxygen isotope study. Meteorit. Planet. Sci. 40, 917-932.

Grady M. M., Wright I. P., Swart P. K. and Pillinger C. T. (1988) The carbon and oxygen isotopic composition of meteoritic carbonates. Geochim. Cosmochim. Acta 52, 28552866. 
Greenwood R. C., Lee M. R., Hutchison R. and Barber D. J. (1994) Formation and alteration of CAIs in Cold Bokkeveld (CM2). Geochim. Cosmochim. Acta 58, 1913-1935.

Guo W. and Eiler J. M. (2007) Temperatures of aqueous alteration and evidence for methane generation on the parent bodies of the CM chondrites. Geochim. Cosmochim. Acta 71, $5565-5575$.

Hanna R. D., Ketcham R. A., Zolensky M. and Behr W. M. (2015) Impact-induced brittle deformation, porosity loss, and aqueous alteration in the Murchison CM chondrite. Geochim. Cosmochim. Acta 171, 256-282.

Hanon P., Robert F. and Chaussidon M. (1998) High carbon concentrations in meteoritic chondrules: A record of metal-silicate differentiation. Geochim. Cosmochim. Acta 62, 903-913.

Hewins R. H., Bourot-Denise M., Zanda B., Leroux H., Barrat J.-A., Humayun M., Göpel C., Greenwood R. C., Franchi I. A., Pont S., Lorand J.-P., Cournède C., Gattacceca J., Rochette P., Kuga M., Marrocchi Y. and Marty B. (2014) The Paris meteorite, the least altered CM chondrite so far. Geochim. Cosmochim. Acta 124, 190-222.

Horita J. and Berndt M. E. (1999) Abiogenic methane formation and isotopic fractionation under hydrothermal conditions. Science 285, 1055-1057.

Horita J., Ueda A., Mizukami K., and Takatori I. (1989) Automatic $\delta \mathrm{D}$ and $\delta^{18} \mathrm{O}$ analyses of multi-water samples using $\mathrm{H}_{2}$-water and $\mathrm{CO}_{2}$-water equilibration methods with a common equilibration set-up. Appl. Rad. Isot. 40: 801-805.

Horstmann M., Vollmer C., Birth M. I. F., Chaussidon M., Gurenko A. and Bischoff A. (2014) Tracking aqueous alteration of CM chondrites-Insight from in-situ oxygen isotope measurements of calcite. Lunar Planet. Sci. 45. Lunar Planet. Inst., Houston. \#1761 (abstr.).

Howard K. T., Alexander C. M. O., Schrader D. L. and Dyl K. A. (2015) Classification of hydrous meteorites (CR, $\{\mathrm{CM}\}$ and $\{\mathrm{C} 2\}$ ungrouped) by phyllosilicate fraction: PSDXRD modal mineralogy and planetesimal environments. Geochim. Cosmochim. Acta 149, 206-222.

Howard K. T., Benedix G. K., Bland P. A. and Cressey G. (2009) Modal mineralogy of CM2 chondrites by X-ray diffraction (PSD-XRD). Part 1: Total phyllosilicate abundance and the degree of aqueous alteration. Geochim. Cosmochim. Acta 73, 4576-4589.

Johnson C. A. and Prinz M. (1993) Carbonate compositions in CM and CI chondrites and implications for aqueous alteration. Geochim. Cosmochim. Acta 57, 2843-2852.

Ketcham R. A. (2005a) Computational methods for quantitative analysis of three-dimensional features in geological specimens. Geospherei. 1, 32-41.

Ketcham R. A. (2005b) Three-dimensional grain fabric measurements using high-resolution X-ray computed tomography. J. Struct. Geol. 27, 1217-1228.

Kurat G., Koeberl C., Presper T., Brandstätter F. and Maurette M. (1994) Petrology and geochemistry of Antarctic micrometeorites. Geochim. Cosmochim. Acta 58, 3879- 
Lécuyer C., Hutzler A., Amiot R., Daux V., Grosheny D., Otero O., Martineau F., Fourel F.,

Balter V. and Reynard B. (2012) Carbon and oxygen isotope fractionations between aragonite and calcite of shells from modern molluscs. Chem. Geol. 332-333, 92-101.

Lee M. R. and Ellen R. (2008) Aragonite in the Murray (CM2) carbonaceous chondrite: implications for parent body compaction and aqueous alteration. Meteorit. Planet. Sci. 43, 1219-1231.

Lee M. R., Lindgren P. and Sofe M. R. (2014) Aragonite, breunnerite, calcite and dolomite in the CM carbonaceous chondrites: High fidelity recorders of progressive parent body aqueous alteration. Geochim. Cosmochim. Acta 144, 126-156.

Lee M. R., Lindgren P., Sofe M. R., Alexander C. M. O. and Wang J. (2012) Extended chronologies of aqueous alteration in the CM2 carbonaceous chondrites: Evidence from carbonates in Queen Alexandra Range 93005. Geochim. Cosmochim. Acta 92, $148-169$.

Lee M. R., Sofe M. R., Lindgren P., Starkey N. A. and Franchi I. A. (2013) The oxygen isotope evolution of parent body aqueous solutions as recorded by multiple carbonate generations in the Lonewolf Nunataks 94101 CM2 carbonaceous chondrite. Geochim. Cosmochim. Acta 121, 452-466.

Lindgren P., Hanna R. D., Dobson K. J., Tomkinson T. and Lee M. R. (2015) The paradox between low shock-stage and evidence for compaction in $\mathrm{CM}$ carbonaceous chondrites explained by multiple low-intensity impacts. Geochim. Cosmochim. Acta 148, 159-178.

Lindgren P., Lee M. R., Sofe M. and Burchell M. J. (2011) Microstructure of calcite in the CM2 carbonaceous chondrite LON 94101: Implications for deformation history during and/or after aqueous alteration. Earth Planet. Sci. Lett. 306, 289-298.

Lindgren P., Lee M. R., Sofe M. R. and Zolensky M. E. (2013) Clasts in the CM2 carbonaceous chondrite Lonewolf Nunataks 94101: Evidence for aqueous alteration prior to complex mixing. Meteorit. Planet. Sci. 48, 1074-1090.

Lindgren P., Lee M. R., Starkey N. A. and Franchi I. A. (2017) Fluid evolution in CM carbonaceous chondrites tracked through the oxygen isotopic compositions of carbonates. Geochim. Cosmochim. Acta 204, 240-251.

Luo W. and Wang S. (2009) Transmission of $\delta$ 13C signals and its paleoclimatic implications in Liangfeng Cave system of Guizhou Province, SW China. Environ. Earth Sci. 59, 655-661.

Marrocchi Y., Bekaert D. V. and Piani L. (2018) Origin and abundance of water in carbonaceous asteroids. Earth Planet. Sci. Lett. 482, 23-32.

Marrocchi Y., Gounelle M., Blanchard I., Caste F. and Kearsley A. T. (2014) The Paris CM chondrite: Secondary minerals and asteroidal processing. Meteorit. Planet. Sci. 49, 1232-1249. 
Martin P. M. and Mills A. A. (1980) Preferred chondrule orientations in meteorites. Earth Planet. Sci. Lett. 51, 18-25.

McSween H. Y. (1979) Are carbonaceous chondrites primitive or processed? A review. Rev. Geophys. 17, 1059-1078.

Metzler K., Bischoff A. and Stöffler D. (1992) Accretionary dust mantles in CM chondrites: Evidence for solar nebula processes. Geochim. Cosmochim. Acta 56, 2873-2897.

Mook W. G., Bommerson J. C. and Staverman W. H. (1974) Carbon isotope fractionation between dissolved bicarbonate and gaseous carbon dioxide. Earth Planet. Sci. Lett. 22, $169-176$.

Morbidelli A., Bitsch B., Crida A., Gounelle M., Guillot T., Jacobson S., Johansen A., Lambrechts M and Lega E. (2016) Fossilized condensation lines in the Solar System protoplanetary disk. Icarus 267, 368-376.

Nakamura T. (2000) Impact-Induced Textural Changes of CV Carbonaceous Chondrites: Experimental Reproduction. Icarus 146, 289-300.

Nakamura T. (2005) Post-hydration thermal metamorphism of carbonaceous chondrites. $J$. Mineral. Petrol. Sci. 100, 260-272.

Nakamura T., Tomeoka K., Sekine T. and Takeda H. (1995) Impact-induced chondrule flattening in the Allende CV3 carbonaceous chondrite: Shock experiments. Meteorit. Planet. Sci. 30, 344-347.

Nakamura T., Tomeoka K. and Takeda H. (1992) Shock effects of the Leoville CV carbonaceous chondrite: a transmission electron microscope study. Earth Planet. Sci. Lett. 114, 159-170.

Nakato A., Nakamura T., Kitajima F. and Noguchi T. (2008) Evaluation of dehydration mechanism during heating of hydrous asteroids based on mineralogical and chemical analysis of naturally and experimentally heated CM chondrites. Earth Planets Space 60, 855-864.

Palmer E. E. and Lauretta D. S. (2011) Aqueous alteration of kamacite in CM chondrites. Meteorit. Planet. Sci. 46, 1587-1607.

Pignatelli I., Mugnaioli E. and Marrocchi Y. (2018) Cronstedtite polytypes in the Paris meteorite. European Journal of Mineralogy. DOI: 10.1127/ejm/2018/0030-2713.

Pignatelli I., Marrocchi Y., Mugnaioli E., Bourdelle F. and Gounelle M. (2017) Mineralogical, crystallographic and redox features of the earliest stages of fluid alteration in CM chondrites. Geochim. Cosmochim. Acta 209, 106-122.

Pignatelli I., Marrocchi Y., Vacher L. G., Delon R. and Gounelle M. (2016) Multiple precursors of secondary mineralogical assemblages in $\mathrm{CM}$ chondrites. Meteorit. Planet. Sci. 51, 785-805.

Proskurowski G. (2010) Abiogenic hydrocarbon production at the geosphere-biosphere interface via serpentinization reactions. In: Timmis, K.N., McGenity, T., van der 
Meer, J.R., de Lorenzo, V. (Eds.), Handbook of Hydrocarbon and Lipid Microbiology. Springer, Berlin Heidelberg, pp. 215-231.

Riciputi L. R., McSween H. Y., Johnson C. A. and Prinz M. (1994) Minor and trace element concentrations in carbonates of carbonaceous chondrites, and implications for the compositions of coexisting fluids. Geochim. Cosmochim. Acta 58, 1343-1351.

Rollion-Bard C., Mangin D. and Champenois M. (2007) Development and application of oxygen and carbon isotopic measurements of biogenic carbonates by ion microprobe. Geostand. Geoanalytical Res. 31, 39-50.

Rubin A. E. (2015) An American on Paris: extent of aqueous alteration of a CM chondrite and the petrography of its refractory and amoeboid olivine inclusions. Meteorit. Planet. Sci. 50, 1595-1612.

Rubin A. E. (2012) Collisional facilitation of aqueous alteration of CM and CV carbonaceous chondrites. Geochim. Cosmochim. Acta 90, 181-194.

Rubin A. E. and Ma C. (2017) Meteoritic minerals and their origins. Chem. Erde - Geochem. 77, 325-385.

Rubin A. E. and Swindle T. D. (2011) Flattened chondrules in the LAP 04581 LL5 chondrite: Evidence for an oblique impact into LL3 material and subsequent collisional heating. Meteorit. Planet. Sci. 46, 587-600.

Rubin A. E., Trigo-Rodríguez J. M., Huber H. and Wasson J. T. (2007) Progressive aqueous alteration of CM carbonaceous chondrites. Geochim. Cosmochim. Acta 71, 23612382 .

Rubin A. E. and Wasson J. T. (1986) Chondrules in the Murray CM2 meteorites and compositional differences between $\mathrm{CM}-\mathrm{CO}$ and ordinary chondrite chondrules. Geochim. Cosmochim. Acta 50, 307-315.

Scott E. R. D., Keil K. and Stöffler D. (1992) Shock metamorphism of carbonaceous chondrites. Geochim. Cosmochim. Acta 56, 4281-4293.

Scott E. R. D. and Taylor G. J. (1983) Chondrules and other components in C, O, and E chondrites: Similarities in their properties and origins. J. Geophys. Res. Solid Earth 88, B275-B286.

Sephton M. A. and Botta O. (2005) Recognizing life in the Solar System: guidance from meteoritic organic matter. Int. J. Astrobiol. 4, 269-276.

Sofe M. (2013) The oldest carbonate minerals on Earth: Insights into the early history of the Solar System. Ph. D. thesis, Univ. Glasgow.

Sneyd D. S., McSween H. Y., Sugiura N., Strangway D. W. and Nord G. L. (1988) Origin of Petrofabrics and Magnetic Anisotropy in Ordinary Chondrites. Meteoritics 23, 139149.

Stiller M., Rounick J. S. and Shasha S. (1985) Extreme carbonisotope enrichments in evaporating brines. Nature 316, 434-435. 
Stöffler D., Keil K. and R.D S. E. (1991) Shock metamorphism of ordinary chondrites. Geochim. Cosmochim. Acta 55, 3845-3867.

Suavet C., Alexandre A., Franchi I. A., Gattacceca J., Sonzogni C., Greenwood R. C., Folco L. and Rochette P. (2010) Identification of the parent bodies of micrometeorites with high-precision oxygen isotope ratios. Earth Planet. Sci. Lett. 293, 313-320.

Suttle M. D., Genge M. J. and Russell S. S. (2017) Shock fabrics in fine-grained micrometeorites. Meteorit. Planet. Sci. 52, 2258-2274.

Telus M., Alexander C. M. O'D., Wang J. and Hauri E. H. (2017) In situ analyses of carbonate and magnetite in CM1 chondrites. Lunar Planet. Sci. 48. Lunar Planet. Inst., Houston. \#1725 (abstr.).

Tomeoka K. and Buseck P. R. (1985) Indicators of aqueous alteration in CM carbonaceous chondrites: Microtextures of a layered mineral containing Fe, S, O and Ni. Geochim. Cosmochim. Acta 49, 2149-2163.

Tomeoka K., Yamahana Y. and Sekine T. (1999) Experimental shock metamorphism of the Murchison CM carbonaceous chondrite. Geochim. Cosmochim. Acta 63, 3683-3703.

Tyra M. A., Farquhar J., Guan Y. and Leshin L. A. (2012) An oxygen isotope dichotomy in CM2 chondritic carbonates-A SIMS approach. Geochim. Cosmochim. Acta 77, 383395.

Tyra M. A., Farquhar J., Wing B. A., Benedix G. K., Jull A. J. T., Jackson T. and Thiemens M. H. (2007) Terrestrial alteration of carbonate in a suite of Antarctic CM chondrites: Evidence from oxygen and carbon isotopes. Geochim. Cosmochim. Acta 71, 782-795.

Tyra M., Brearley A. and Guan Y. (2016) Episodic carbonate precipitation in the CM chondrite ALH 84049: An ion microprobe analysis of $\mathrm{O}$ and $\mathrm{C}$ isotopes. Geochim. Cosmochim. Acta 175, 195-207.

Vacher L. G., Marrocchi Y., Verdier-Paoletti M. J., Villeneuve J. and Gounelle M. (2016) Inward radial mixing of interstellar water ices in the solar protoplanetary disk. Astrophys. J. 827, L1.

Vacher L. G., Marrocchi Y., Villeneuve J., Verdier-Paoletti M. J. and Gounelle M. (2017) Petrographic and $\mathrm{C} \& \mathrm{O}$ isotopic characteristics of the earliest stages of aqueous alteration of CM chondrites. Geochim. Cosmochim. Acta 213, 271-290.

Verdier-Paoletti M. J., Marrocchi Y., Avice G., Roskosz M., Gurenko A. and Gounelle M. (2017a) Oxygen isotope constraints on the alteration temperatures of CM chondrites. Earth Planet. Sci. Lett. 458, 273-281.

Verdier-Paoletti M. J., Vacher L. G., Marrocchi Y., Gattacceca J., Sonzogni C., Gurenko A. and Gounelle M. (2017b) Teting the genetic relationship between fluid alteration and brecciation: the case of Boriskino. In 80th Annual Meeting of the Meteoritical Society. \#6081 (abstr.).

Watt L. E., Bland P. A., Prior D. J. and Russell S. S. (2006) Fabric analysis of Allende matrix using EBSD. Meteorit. Planet. Sci. 41, 989-1001. 
1006 White S. N. (2009) Laser Raman spectroscopy as a technique for identification of seafloor hydrothermal and cold seep minerals. Chem. Geol. 259, 240-252.

1008 Woodcock N. H. and Naylor M. (1983) Randomness testing in three-dimensional orientation data. J. Struct. Geol. 5, 539-548.

1010

Zolensky M. E., Mittlefehldt D. W., Lipschutz M. E., Wang M.-S., Clayton R. N., Mayeda T.

1011 K., Grady M. M., Pillinger C. and B D. (1997) CM chondrites exhibit the complete

1012 petrologic range from type 2 to 1. Geochim. Cosmochim. Acta 61, 5099-5115.

1013 Zolotov M. Y. (2014) Formation of brucite and cronstedtite-bearing mineral assemblages on 1014 Ceres. Icarus 228, 13-26.

1015

1016 


\section{FIGURE CAPTIONS}

1018

1019 Figure 1: (a) Full 3D volume rendering of the bulk sample of Boriskino using X-ray 1020 computed tomography (XCT). The dashed line represents the location of (b). (b) XCT slice 1021 \#1005 from the full volume. The elliptical dark-toned objects are interpreted as type I 1022 chondrules.

1023

1024

Figure 2: Back-scattered electron (BSE) mosaics of the two polished sections of the CM2 Boriskino (sections \#3 \& \#4). (a) BSE mosaic of Boriskino section \#3 in which the different lithologies are marked (numbered white circles) and delimited (dashed lines). Analyzed

1027 Type1 a aragonites are represented by green diamonds, Type 1a calcites by green points, Type

1028 2a calcites by red circles and calcite veins by purple triangle. (b) BSE mosaic of Boriskino section \#4 in which Ca-carbonate grains and different lithologies are indicated and outlined. The arbitrary orientation of two sections used for petrofabric determination is represented by

1031 the axis at the bottom left of the figure (the horizontal $=0^{\circ}$ ).

1032

1033 Figure 3: BSE mosaics of delimited regions of the three lithologies in section \#4. (a) BSE mosaic of lithology 1 (number in white circle) in contact with lithology 2 (delimited by the dashed line). The Type 2a calcite grain is outlined with a red dashed line. Sph: sulphide, Phy: phyllosilicate. (b) BSE mosaic of lithology 2 in contact with lithology 1. (c) BSE mosaic of a 1037 specific region of lithology 3 in contact with lithology 1 and other lithologies. The Type 1a 1038 aragonite grains are represented by green diamonds.

1040 Figure 4: (a) BSE image of Type 1a aragonite (A) surrounded by a fine rim of phyllosilicate 1041 (Phy) in lithology 3 (white circle, \#4). (b) BSE image of Type 1a calcite (C) surrounded by a 
1042 fine rim of phyllosilicate in lithology 3 (\#4). (c) BSE image of polycrystalline aggregates of

1043 Type 2 calcite (C), exhibiting phyllosilicate (Phy) and sulphide (Sph), located in the matrix of

1044 lithology 1 (\#3). (d) BSE image of a calcite vein, hundreds of micrometers in length and ten

1045 of micrometers in width, in lithology $1(\# 3)$. The large white arrows indicate the mean

1046 orientations of the petrofabrics of the three lithologies in section \#4 as determined in Fig. 7b,

1047 7c and 7d. The holes on the Fig. a-c show positions of ion probe spots.

1048

1049 Figure 5: (a) Oxygen three-isotope plot for Type 1a aragonite (green diamonds), Type 1a

1050 calcite (green circles), Type 2a calcite (red circles) and the calcite vein (purple triangle) from

1051 this study (errors are given in $2 \sigma$ ). The dashed line represents the linear regression of our 1052 dataset $\left(\delta^{17} \mathrm{O}=0.62( \pm 0.05,2 \sigma) \times \delta^{18} \mathrm{O}-4.3( \pm 1.3,2 \sigma)\right)$. The black star denotes the mean

1053 O-isotopic composition of CM anhydrous silicates (Anhydrous silicate ${ }^{1}$ : Clayton and Mayeda, 1054 1984). (b) $\Delta^{17} \mathrm{O} v s \delta^{18} \mathrm{O}$ plot of the populations 1 (green points) and 2 (red and purple points) 1055 of Ca-carbonates. $\Delta^{17} \mathrm{O}$ represents the deviation from the TFL: $\Delta^{17} \mathrm{O}=\delta^{17} \mathrm{O}-0.52 \times \delta^{18} \mathrm{O}$.

1056 The O-isotopic compositions of the two populations are represented by the grey square 1057 (population 1) and the white and grey square (population 2). TFL: Terrestrial Fractionation 1058 Line, $\delta^{17} \mathrm{O}=0.52 \times \delta^{18} \mathrm{O}$. CMW: CM Water line, $\delta^{17} \mathrm{O}=0.69 \times \delta^{18} \mathrm{O}-2.12$ (Verdier-Paoletti 1059 et al., 2017a). CCAM: Carbonaceous Chondrite Anhydrous Mineral line, $\delta^{17} \mathrm{O}=0.94 \times \delta^{18} \mathrm{O}-$ $1060 \quad 4.2$.

1061

1062 Figure 6: $\delta^{13} \mathrm{C}$ values of Type 1a aragonite (green diamonds), Type 1a calcite (green circles) 1063 and Type $2 \mathrm{a}$ calcite (red circles) from this study (errors are given in $2 \sigma$ ). The mean values of 1064 the Type 1 and Type 2 Ca-carbonates are represented by the green and the red square, 1065 respectively. The in situ data from the literature (grey circles) are also shown in the figure 1066 (CM2.7 Paris ${ }^{1}$ : Vacher et al., 2017; CM2.5 Murchison ${ }^{2}$ : Fujiya et al., 2015; CM2.2-2.3 
1067 Nogoya ${ }^{3}$ : Fujiya et al., 2016; CM1 ALH 831004, ALH 84034, MET 010704: Telus et al., 1068 2017; CM1 ALH 840495: Tyra et al., 2016).

1069

1070 Figure 7: a) BSE image of Type 2a polycrystalline calcite (C) grains located in a flattened 1071 chondrule surrounded by a fine-grained rim (FGR) and accompanied by phyllosilicate (Phy)

1072 and sulphide inclusions (Sph) in lithology 2. The solid white line represents the direction of 1073 the long axis of the fitted chondrule ellipse. The double white arrow indicates the mean 1074 orientation of the petrofabric of this lithology. b) BSE image of another example of Type 2a 1075 polycrystalline calcite (C) grains located in a flattened chondrule in lithology 1 (section \#3). 1076 c) BSE image of a squeezed type I chondrule located in lithology 1 (section \#4). The red 1077 dashed line delimits a Type 2a polycrystalline grain located in the matrix. The matrix that 1078 surrounds the squeezed chondrule is accompanied by numerous patches of phyllosilicate 1079 (Phy) and sulphide (Sph) grains.

1080

1081 Figure 8: Histograms showing the deviation of particles (i.e., chondrule, TCI clump and 1082 olivine grain) from the median azimuth of each lithology according to the method of Rubin 1083 (2012). The blue area represents the Gaussian fits $\left(y=a \times e^{\left(\frac{x-b}{c}\right)^{2}}\right)$ of the data set. (a) 1084 Lithology 1 in section 3 (\#3) has a strong peak near the median azimuth materialized by a 1085 high maximum frequency $(\mathrm{a}=24 \%)$, a low standard deviation $\left(\mathrm{c}=20.5^{\circ}\right)$ and $46 \%$ of the 1086 particles within $10^{\circ}$ of the median azimuth angle $\left(\mathrm{R}^{2}\right.$ of the Gaussian fit $\left.=0.98\right)$. The solid 1087 purple lines and the black dashed lines indicate the mean orientations of the calcite veins and 1088 the fractures, respectively identified in this lithology. The solid black line corresponds to the 1089 median azimuth value normalized to $0^{\circ}$ using the Rubin (2012) method. (b) Lithology 1 in 1090 section $4(\# 4)$ has a weak peak near the median azimuth revealed by an intermediate 1091 maximum frequency $(\mathrm{a}=13 \%)$, an intermediate standard deviation $\left(\mathrm{c}=27^{\circ}\right)$ and $26 \%$ of the 
1092 particles within $10^{\circ}$ of the median azimuth angle $\left(\mathrm{R}^{2}\right.$ of the Gaussian fit $\left.=0.63\right)$. The solid

1093 black line corresponds to the median azimuth value normalized to $0^{\circ}$, but for comparing the

1094 mean directions of the three lithologies in section 4, the mean direction values determined

1095 from the orientation of the section (see Fig. 2) are indicated. (c) Lithology 2 in section 4 (\#4)

1096 also has weak peak near the median azimuth demonstrated by a low maximum frequency $(\mathrm{a}=$

$109710 \%)$, a high standard deviation $\left(\mathrm{c}=34^{\circ}\right)$ and $21 \%$ of the particles within $10^{\circ}$ of the median

1098 azimuth angle $\left(\mathrm{R}^{2}\right.$ of the Gaussian fit $\left.=0.48\right)$. (d) Lithology 3 in section 4 (\#4) has a strong

1099 peak near the median azimuth confirmed by a high maximum frequency $(\mathrm{a}=22 \%)$, a low

1100 standard deviation $\left(\mathrm{c}=21^{\circ}\right)$ and $41 \%$ of the particles within $10^{\circ}$ of the median azimuth angle

$1101 \quad\left(\mathrm{R}^{2}\right.$ of the Gaussian fit $\left.=0.98\right)$.

1102

1103 Figure 9: Orientation plot of fitted ellipsoid from bulk X-ray computed tomography analyses 1104 of a type I chondrule in Boriskino. (a) Projection of the primary axes (R1) of the fitted 1105 ellipsoid (black circles) and the mean value (V1) and pole value (V3) of the data set (red 1106 diamonds). The blue color gradient represents the density contour values of the data set. $\mathrm{C}=$ 1107 the strength parameter, $\mathrm{K}=$ the shape parameter and $\mathrm{n}=$ the number of extracted objects. (b)

1108 Projection of the tertiary axes (R3) of the fitted ellipsoid (black circles) and the mean value 1109 (V1) and pole value (V3) of the data set (blue diamonds). The red color gradient represents 1110 the density contour values of the data set.

1112 Figure 10: Schematic diagram representing the main processes controlling the oxygen 1113 isotopic compositions of Ca-Carbonates. The main trend, with a slope in the range 0.62-0.70 1114 (dashed line, see text), results from O-isotopic exchange between ${ }^{17,18} \mathrm{O}$-rich $\mathrm{CM}$ primordial 1115 water (blue point, Fujiya, 2018) and anhydrous silicates (black star, Clayton and Mayeda, 1116 1984). For a fluid with a given $\Delta^{17} \mathrm{O}$ value, a thermal gradient can occur during carbonate 
1117 precipitation, generating a shift of carbonate O-isotopic compositions along a slope of 0.52

1118 for a given degree of isotopic exchange. TFL: Terrestrial Fractionation Line, CCAM:

1119 Carbonaceous Chondrite Anhydrous Mineral line.

1121 Figure 11: Relationship between intensity of a single shock pressure and mean chondrule 1122 aspect ratio in an experimental shock on the CM Murchison ${ }^{1}$ (solid black line and white 1123 circle; Tomeoka et al., 1999) and on the CV Allende ${ }^{2}$ (black dotted line and black circle;

1124 Nakamura et al., 2000). The mean X-ray computed tomography (XCT) aspect ratio of the

1125 Boriskino type I chondrules (yellow square) and Murchison ${ }^{3}$ dark-toned XCT objects (purple 1126 square; Hanna et al., 2015) is reported on the CV and CM trends. The light grey rectangle that 1127 cuts the CM trend represents the end of the correlation and the effects of the CM shock 1128 experiments above $30 \mathrm{GPa}$ (Tomeoka et al., 1999).

1130 Figure 12: Relationship between degree of alteration $v s$ percentage of particles with long 1131 axes within $10^{\circ}$ of the median azimuth. Data from the lithology 1,2 and 3 are represented by 1132 red circles, red square and green circle, respectively. Data and associated correlation from 1133 Rubin (2012) are shown in blue circles and black dashed line, respectively. Percentages of 1134 chondrules alignment with long axis within $10^{\circ}$ from Lindgren et al. (2015) are also 1135 represented (yellow circles).

1137 Figure 13: (a) BSE image showing an interpreted pre-deformation Type 1a Ca-carbonate 1138 (CC) grain isolated in the matrix and a stretched phyllosilicate (Phy), set in the petrofabric of 1139 lithology 3 (section \#4). The double white arrows represent the deformation of the matrix 1140 around the Ca-carbonate grain, as highlighted by the elongation of the phyllosilicate. (b) BSE 
1141 image of stretched clumps of phyllosilicates (Phy) and elongate sulphide (Sph) grains parallel

1142 to the petrofabric of lithology 3 (\#4).

1144 Figure 14: Schematic representation of the thermal and deformation history of the CM parent

1145 body and the expected locations of the Boriskino lithologies at different times. (a) $t_{1}$ :

1146 precipitation of the Type 1a calcite and aragonite of lithology 3 by the decay of the ${ }^{26} \mathrm{Al}$. (b)

$1147 t_{2}$ : formation of fractures and cracks by high intensity impact(s). (c) $t_{3}$ : circulation of fluid

1148 flow within the newly formed fractures in lithologies 1 and 2. (d) $t_{4}$ : release and mixing of

1149 Boriskino's clasts from the CM parent body by a new set of low intensity impact(s).

1151 Figure 15: $\delta^{13} \mathrm{C} v s . \delta^{18} \mathrm{O}$ values for Type 1a aragonite (green diamonds), Type 1a calcite 1152 (green circles) and Type $2 \mathrm{a}$ calcite (red circles) from this study (errors are given in $2 \sigma$ ). We 1153 also show the in situ $\delta^{13} \mathrm{C}-\delta^{18} \mathrm{O}$ data of the Type 1 (light grey circles) and Type 2 (dark grey 1154 circles) calcite from the CM2.2-2.3 Nogoya $^{1}$ (Fujiya et al., 2016). Because of the large 1155 amount of data, the ranges of Ca-carbonate $\delta^{13} \mathrm{C}-\delta^{18} \mathrm{O}$ values reported by Fujiya et al. (2015), 1156 Fujiya et al. (2016), Telus et al. (2017) and Vacher et al. (2017) are shown as light grey 1157 (CM2) and dark grey (CM1) areas for simplicity. The $\delta^{13} \mathrm{C}-\delta^{18} \mathrm{O}$ values of the CM1 MET 115801070 have also been isolated from the literature dataset by black dashed lines (Telus et al., 1159 2017). The $\delta^{13} \mathrm{C}-\delta^{18} \mathrm{O}$ values of $\mathrm{CC} 6, \mathrm{CC} 7, \mathrm{CC} 8$ and $\mathrm{CC} 15$ grains are given as mean values 1160 and errors associated were calculated using the error propagation law.

1162 Figure 16: (a) $\delta^{13} \mathrm{C}$ vs. $\delta^{18} \mathrm{O}$ values for Type 1a aragonite (green diamonds), Type 1a calcite 1163 (green circles) and Type $2 \mathrm{a}$ calcite (red circles) from this study (errors are given in $2 \sigma$ ). The 1164 grey squares represent the in situ $\delta^{13} \mathrm{C}-\delta^{18} \mathrm{O}$ data of the Type $1 \mathrm{Ca}$-carbonates in the CM2.5 1165 Murchison $^{1}$ (Fujiya et al., 2015) and CM2.7 Paris ${ }^{1}$ (Vacher et al., 2017). We also show the in 
1166 situ $\delta^{13} \mathrm{C}-\delta^{18} \mathrm{O}$ data of the Type 1 (light grey circles) and Type 2 (dark grey circles) calcite

1167 from the CM2.2-2.3 Nogoya $^{1}$ (Fujiya et al., 2016). The white triangle lines represent the 1168 predicted isotopic compositions of $\mathrm{CM}$ carbonates as a function of temperature and the mole 1169 fraction of $\mathrm{CO}_{2}$ in a $\mathrm{CO}-\mathrm{CO}_{2}-\mathrm{H}_{2} \mathrm{O}$ system $\left(\delta^{13} \mathrm{C}_{\mathrm{CO}}=-5 \%\right.$ and $\left.\delta^{18} \mathrm{O}_{\mathrm{H} 2 \mathrm{O}}=5 \%\right)\left(\mathrm{CO}-\mathrm{CO}_{2}\right.$ gas ${ }^{1}$ : 1170 Alexander et al., 2015). The white triangles on the model mark $10^{\circ} \mathrm{C}$ intervals. The blue 1171 rectangle represents the predicted range of $\delta^{13} \mathrm{C}-\delta^{18} \mathrm{O}$ values of Ca-carbonates that 1172 precipitated from varying equilibration between ${ }^{17,18} \mathrm{O}$-rich water with ${ }^{12} \mathrm{C}$ - and ${ }^{13} \mathrm{C}$-rich 1173 soluble organic matter at $110^{\circ} \mathrm{C}$ (Vacher et al., 2017). The $\delta^{13} \mathrm{C}-\delta^{18} \mathrm{O}$ values of CC6, CC7, $1174 \mathrm{CC} 8$ and CC15 grains are given as mean values and errors associated were calculated using 1175 the error propagation law. (b) $\delta^{13} \mathrm{C} v s . \delta^{18} \mathrm{O}$ values of the Type 2 a calcite (red circles) from 1176 this study and Type 1 (light grey circles) and Type 2 (dark grey circles) calcite from the CM 1177 Nogoya $^{2}$ (Fujiya et al., 2016) (errors are given in $2 \sigma$ ). The grey dashed line represents the 1178 initial $\delta^{13} C_{\mathrm{HCO}_{\overline{3}_{0}}}$ value of the fluid used in the Rayleigh distillation calculations (see Eq.(2),

$1179 \delta^{13} C_{\mathrm{HCO}_{\overline{3}_{0}}}=30 \%$ ). Percent estimates of dissolved carbon escape from the fluid by Rayleigh 1180 distillation are also shown for a mean temperature of $110^{\circ} \mathrm{C}$. The $\delta^{13} \mathrm{C}-\delta^{18} \mathrm{O}$ values of CC6 1181 and CC8 grains are given as mean values and errors associated were calculated using the error 1182 propagation law. 
$1187 \quad$ FIGURES

1188

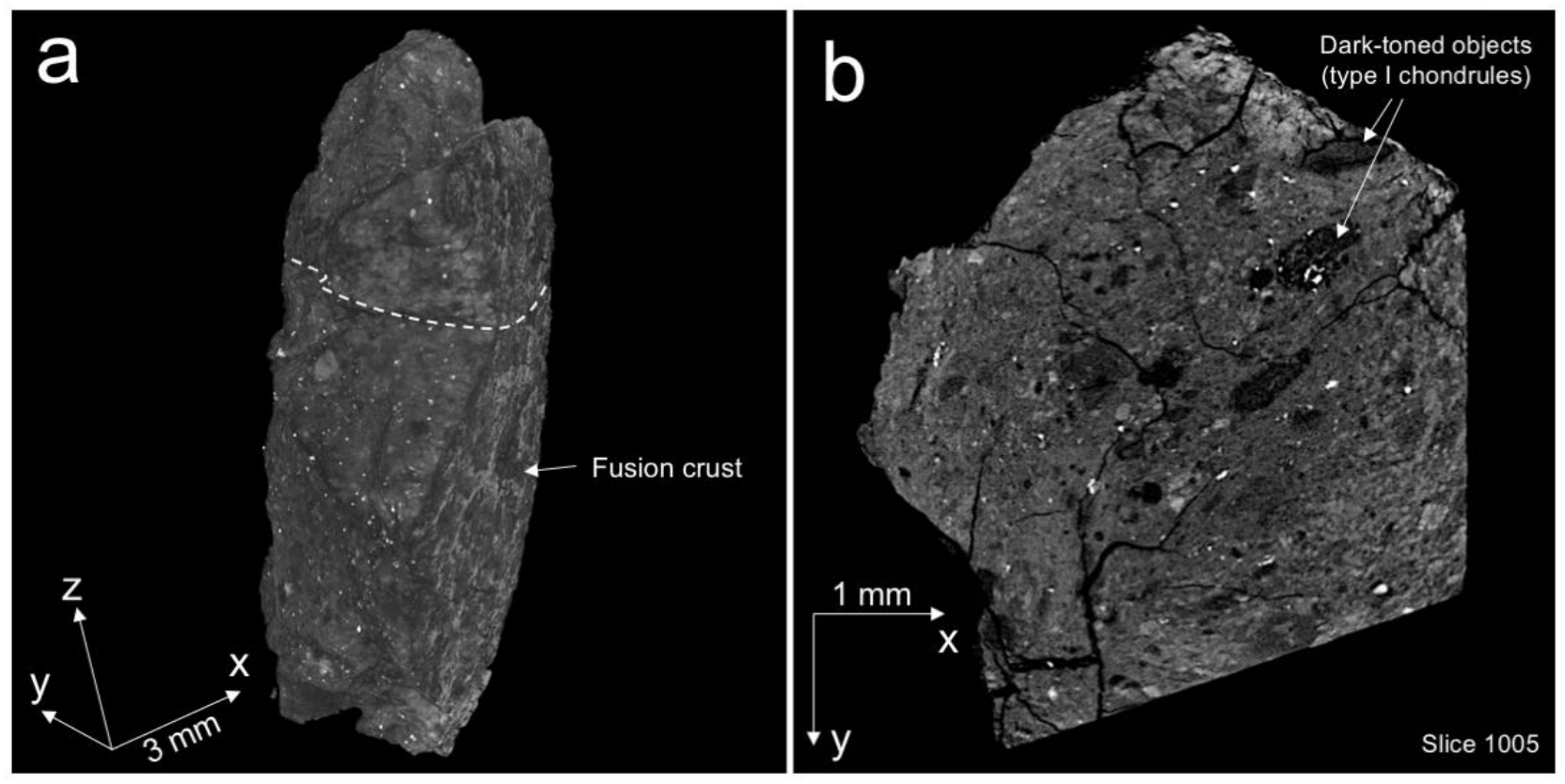

1190

Figure 1

1191 

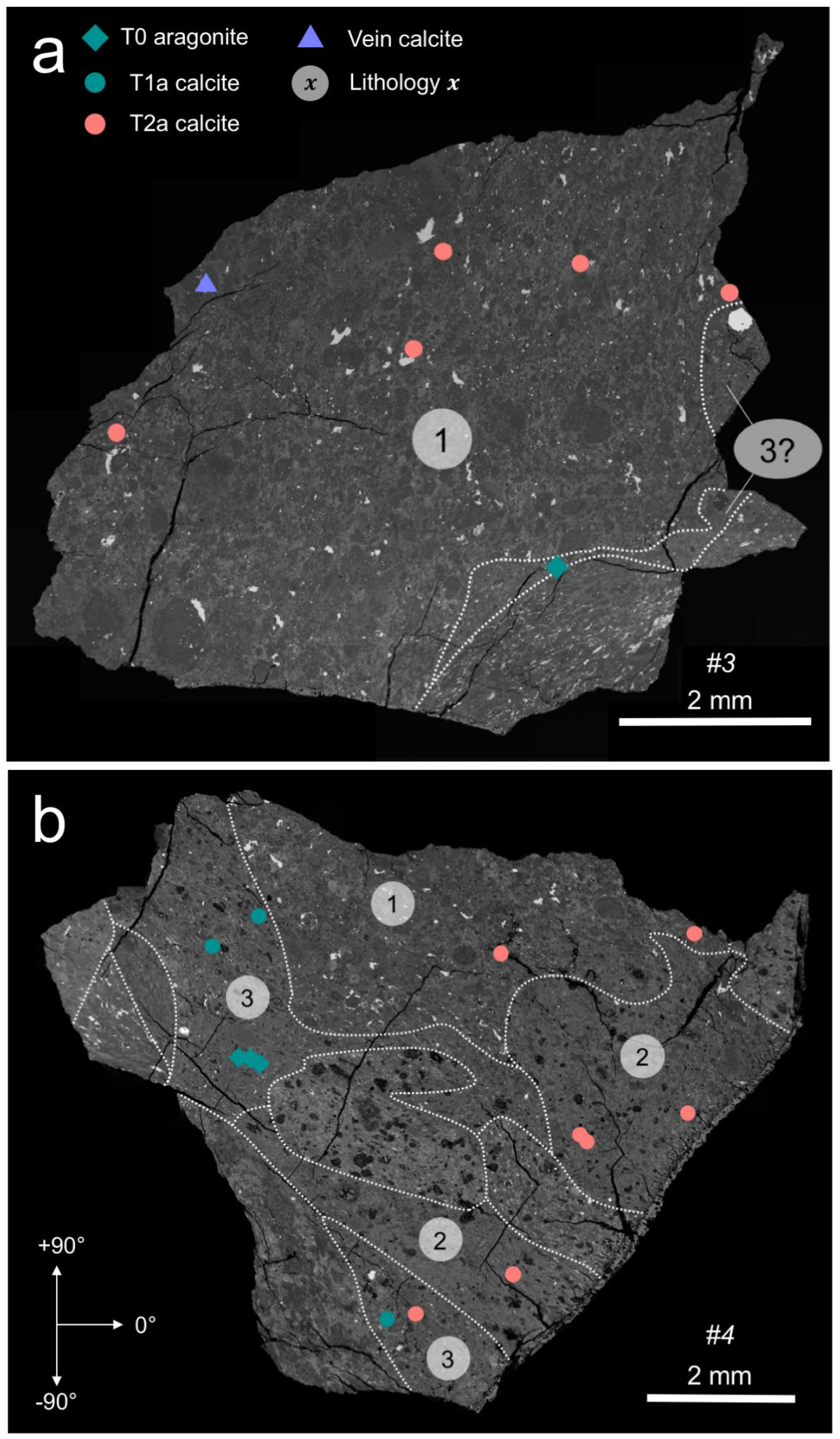


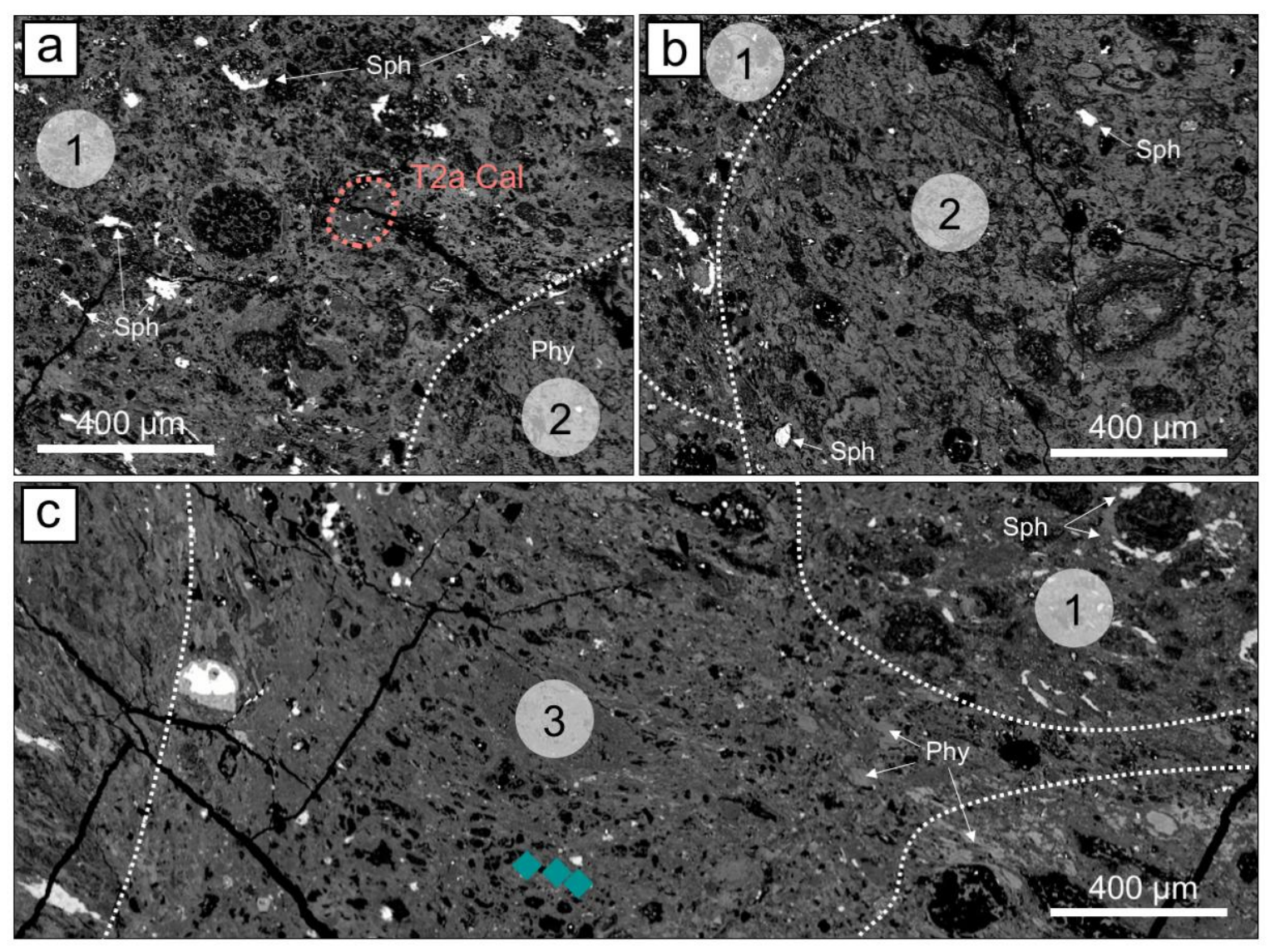

1194

1195

Figure 3 

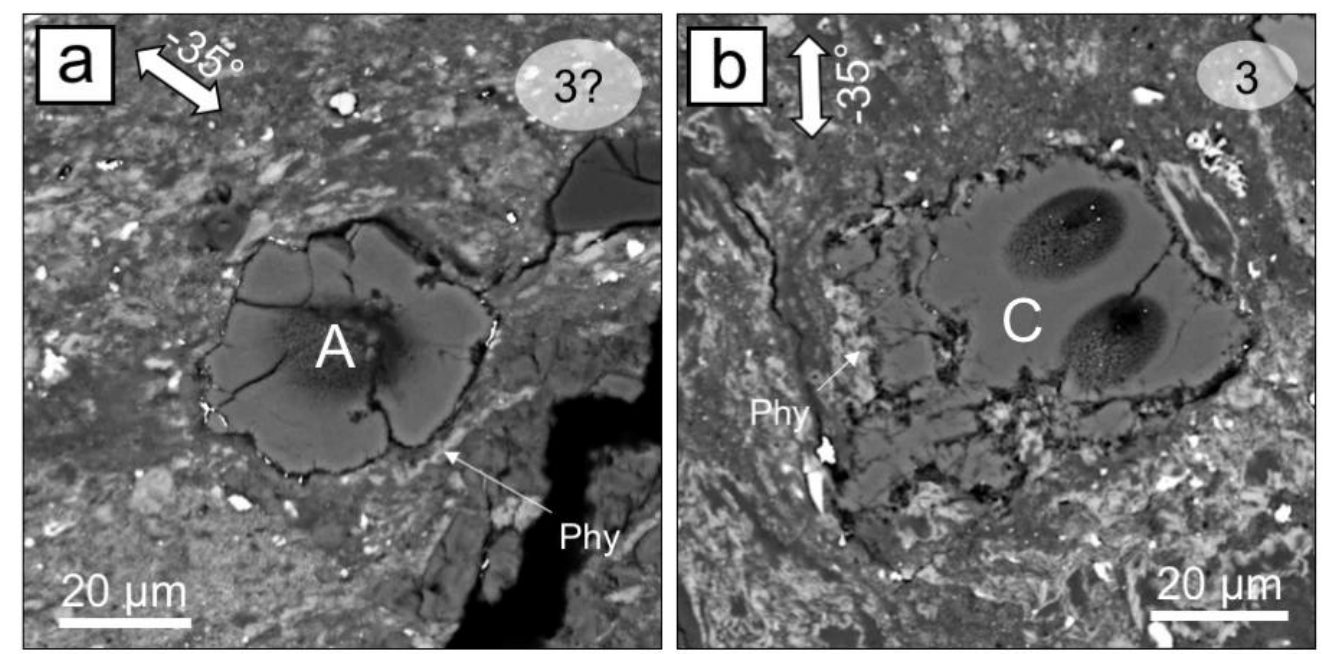

1196
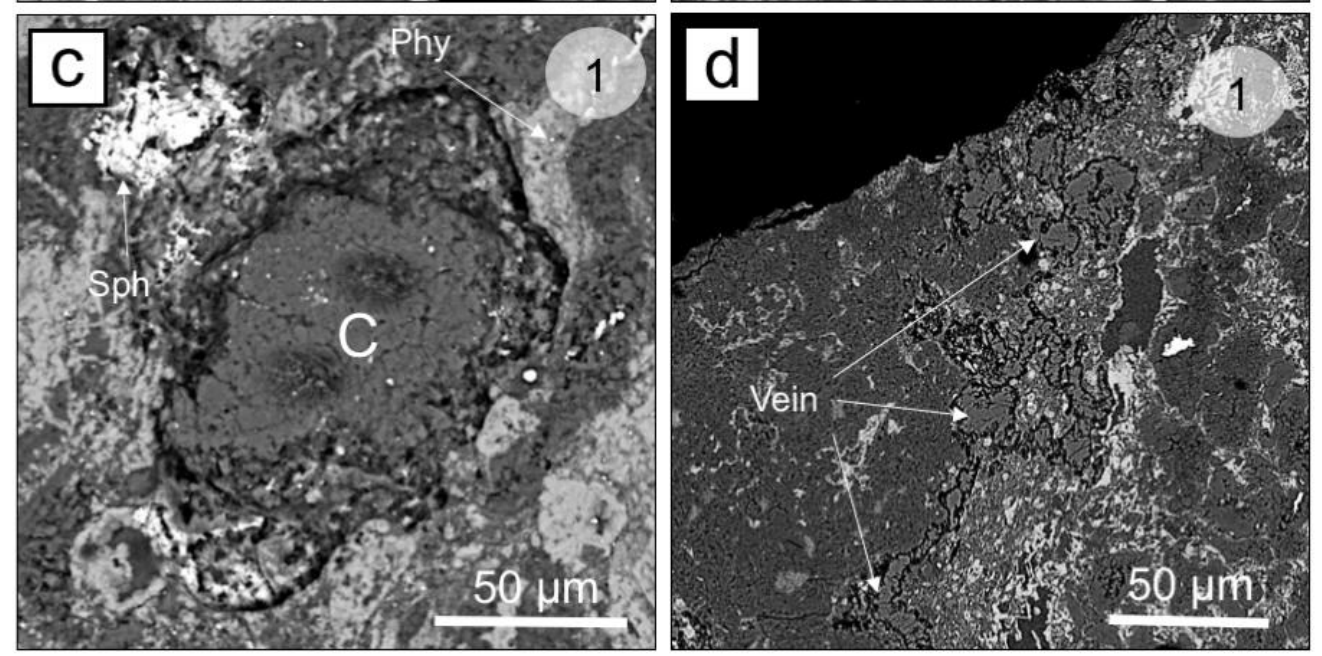

1197

Figure 4 

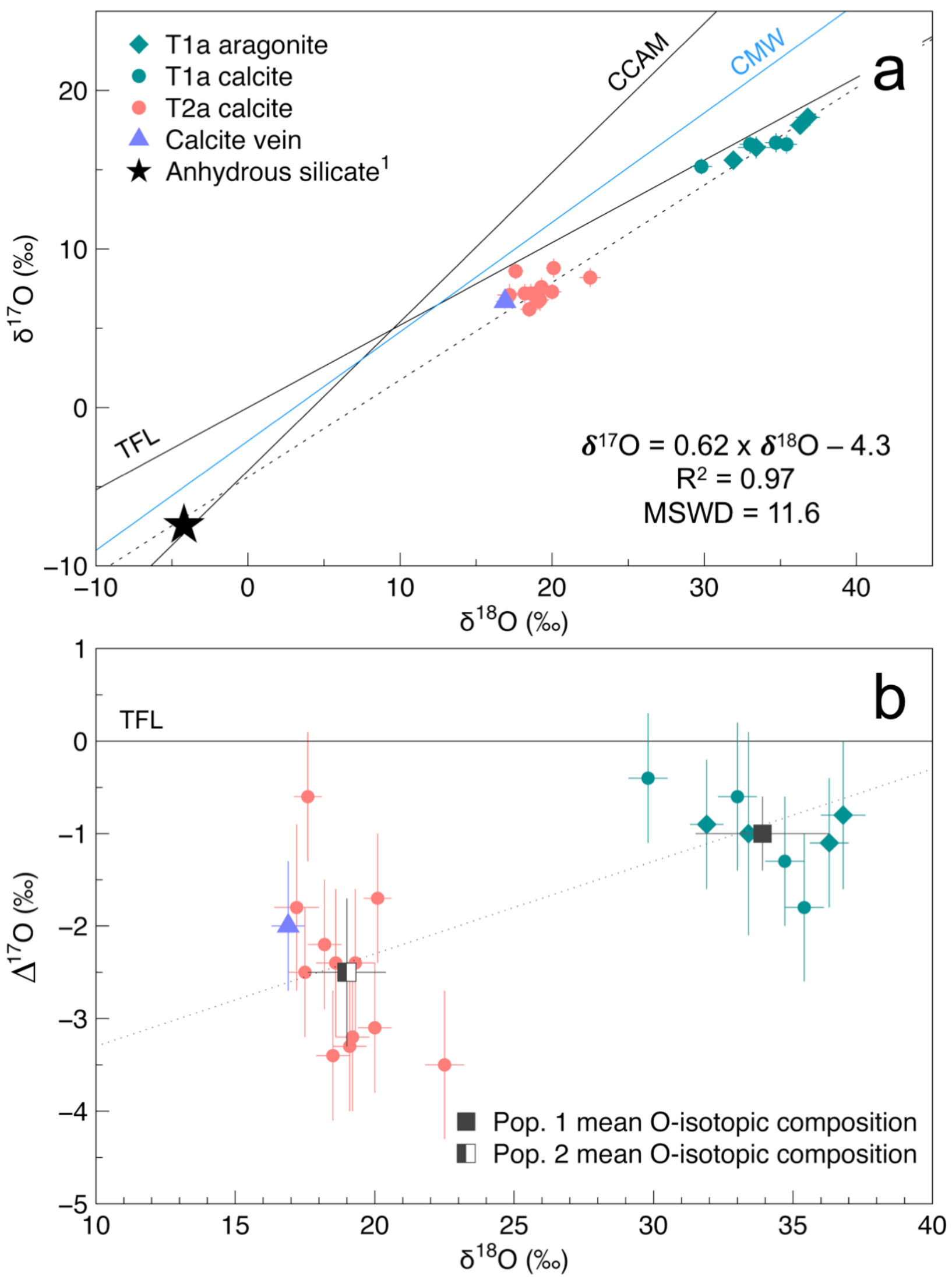

1198 

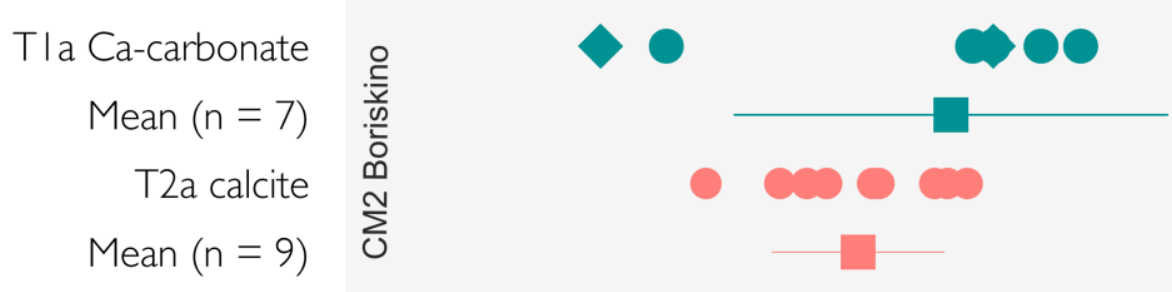

CM 2.7 Paris'

CM 2.5 Murchison ${ }^{2}$

CM 2.2-2.3 Nogoya $^{3}$

CMI ALH $83100^{4}$

CMI ALH $84034^{4}$

CMI ALH $84049^{5}$

CMI MET $01070^{4}$

1201

- T1a aragonite

- T1a calcite

- T2a calcite

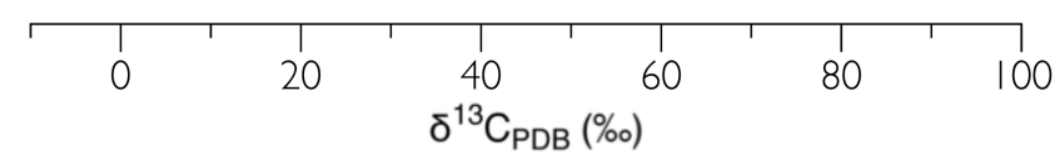

1202

Figure 6

1203 

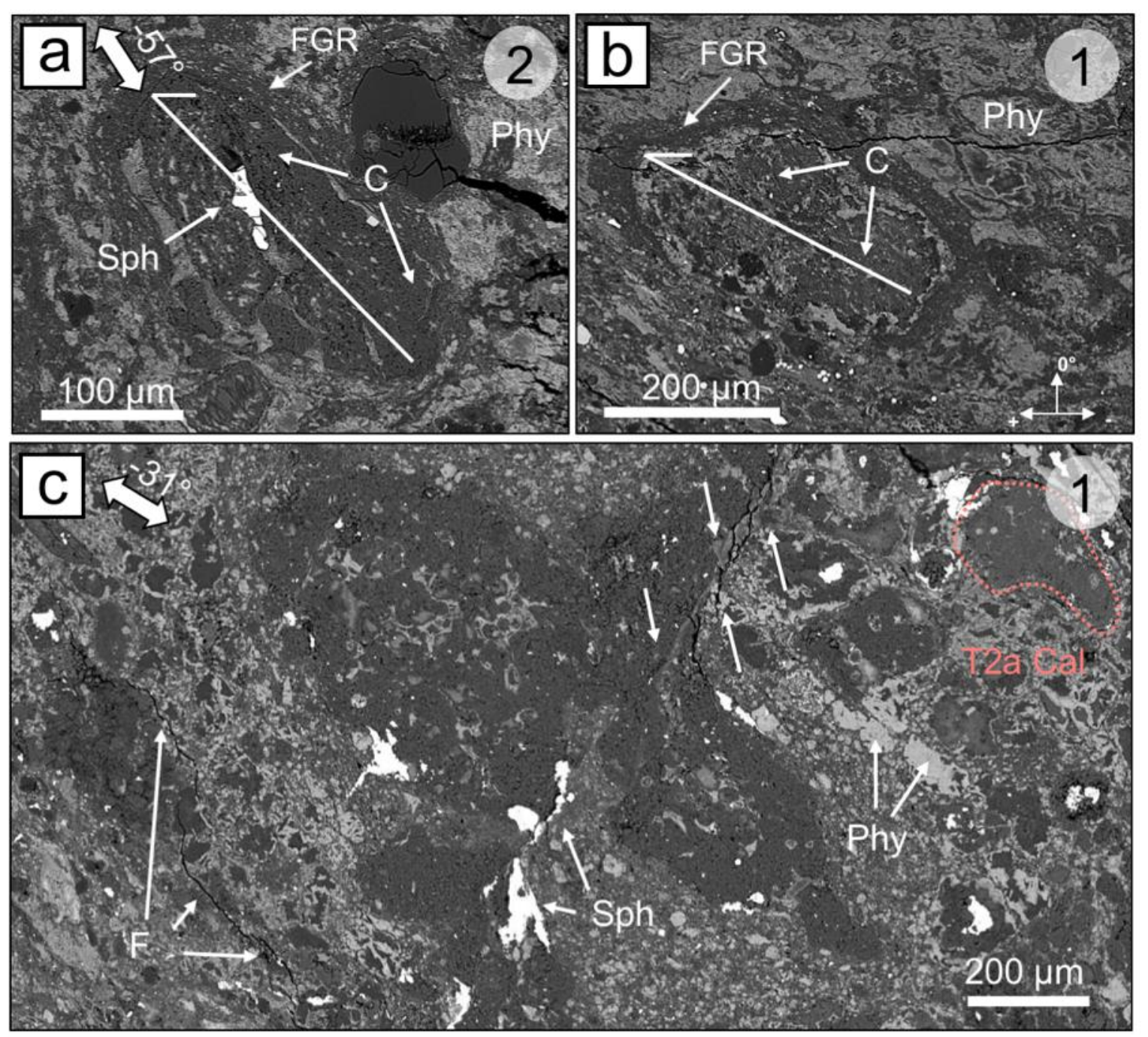

1204

1205

Figure 7

1206 

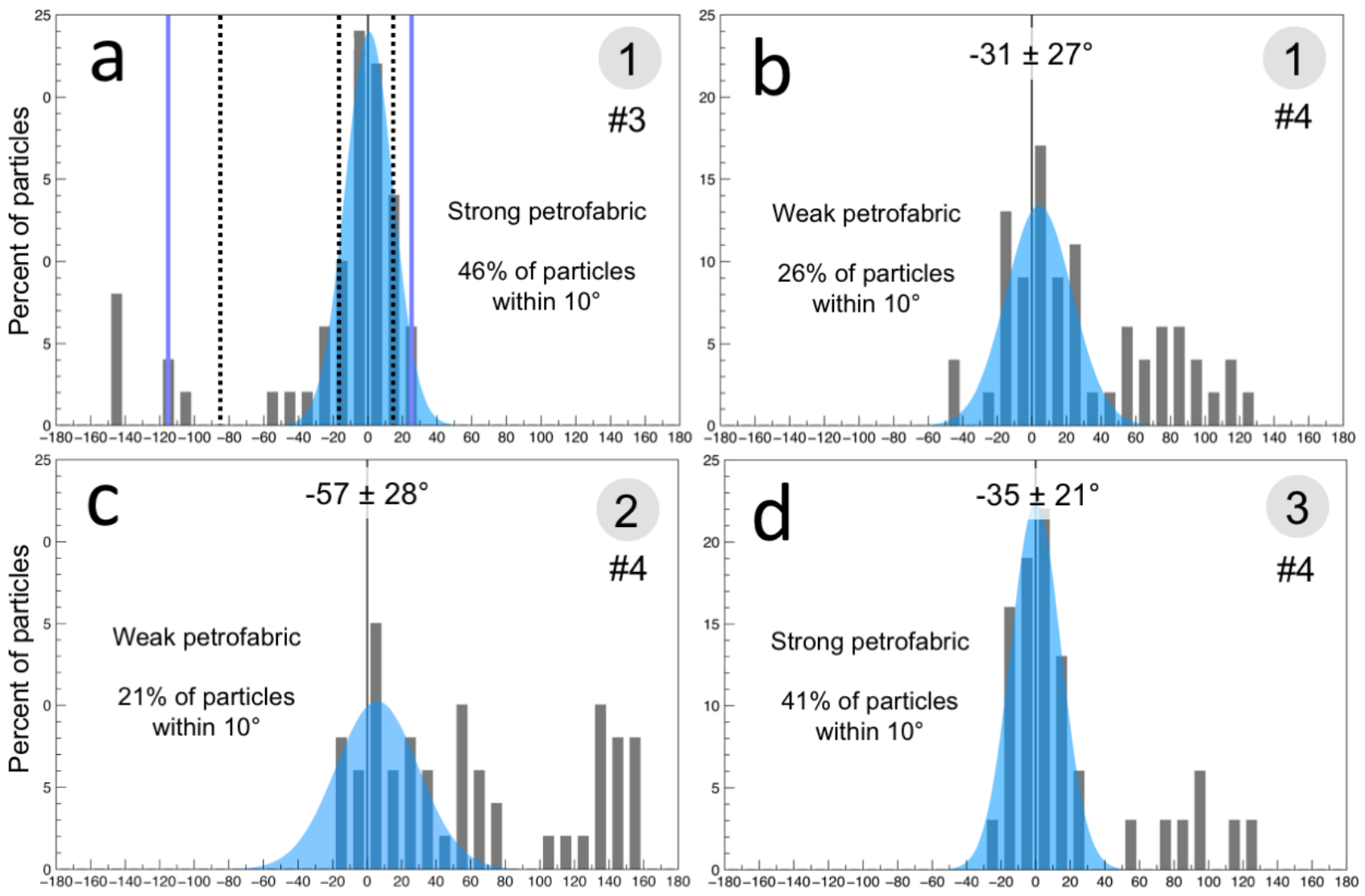

1207

1208

Deviation from median azimuthal angle of particle long axes

1209

Figure 8

1210 

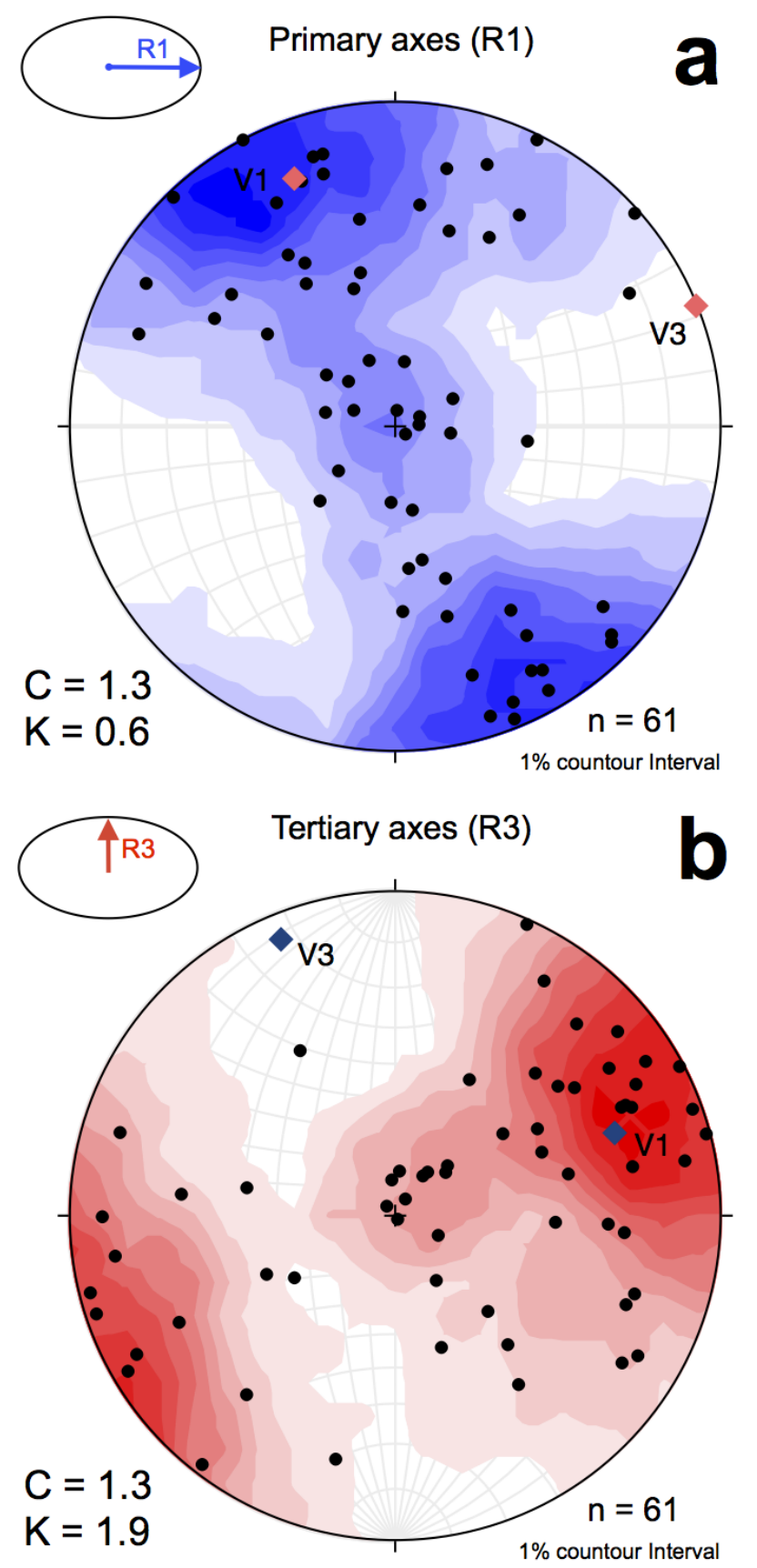
Figure 9 


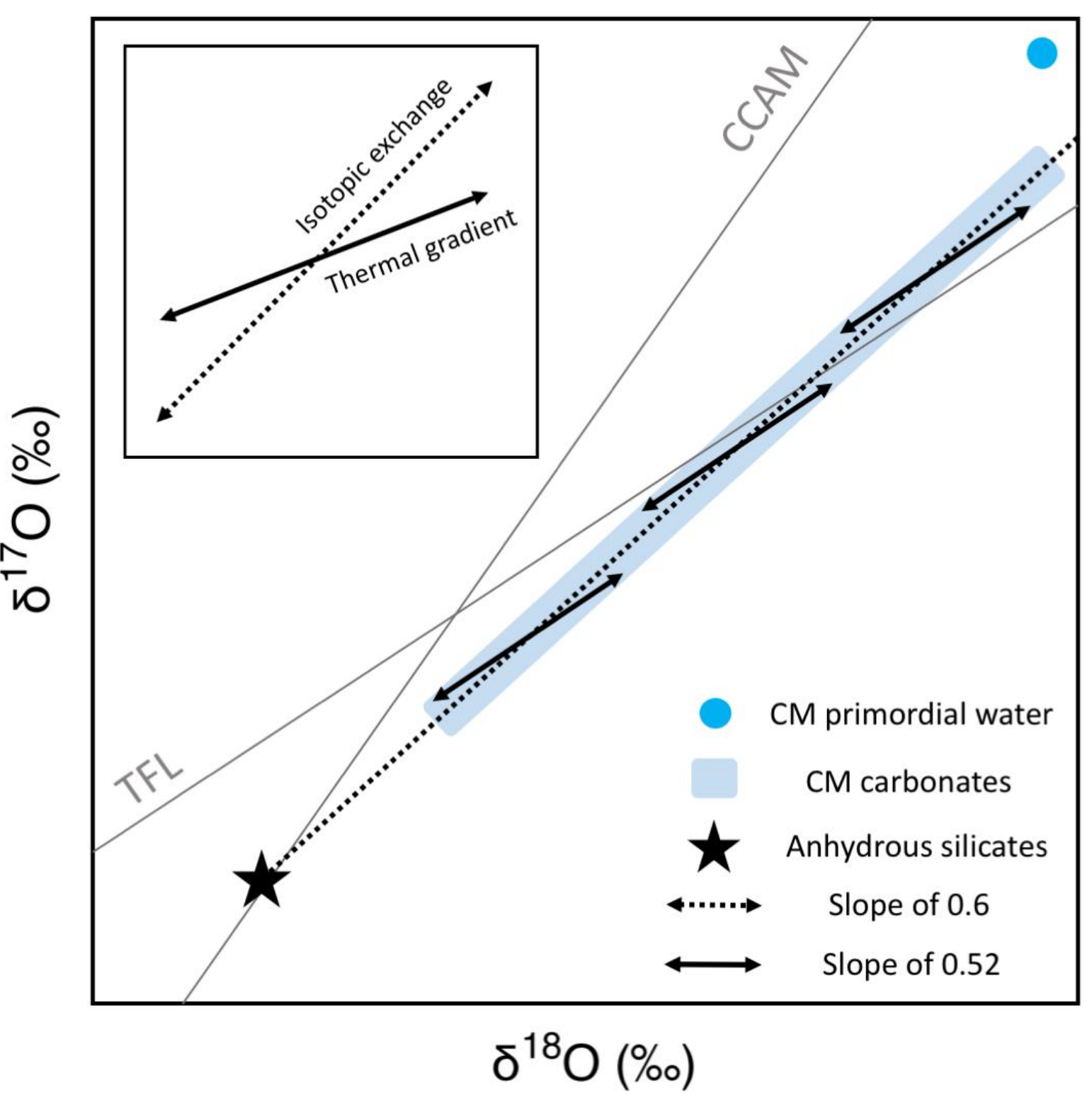

1213

Figure 10 


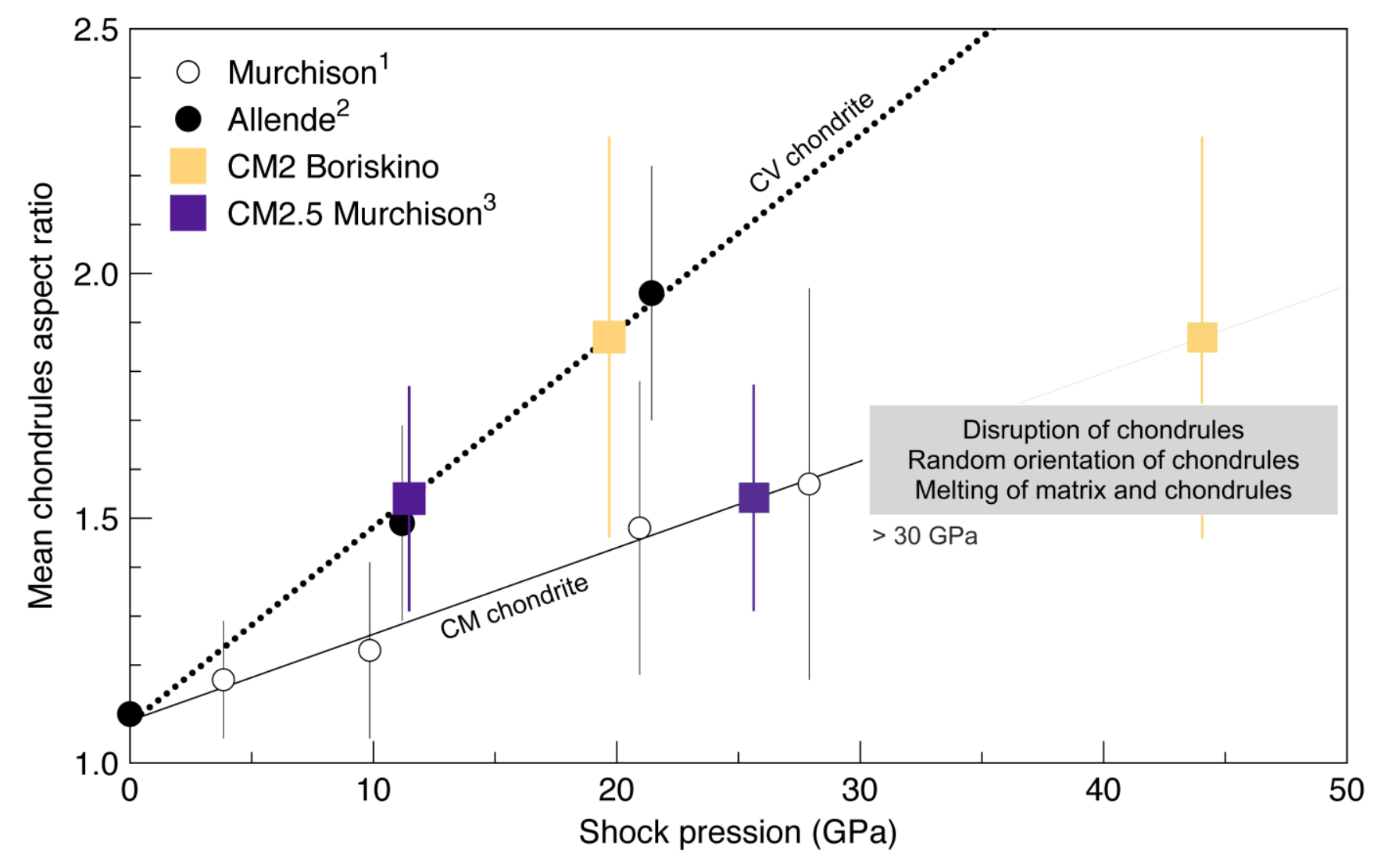

1216

Figure 11

1217 


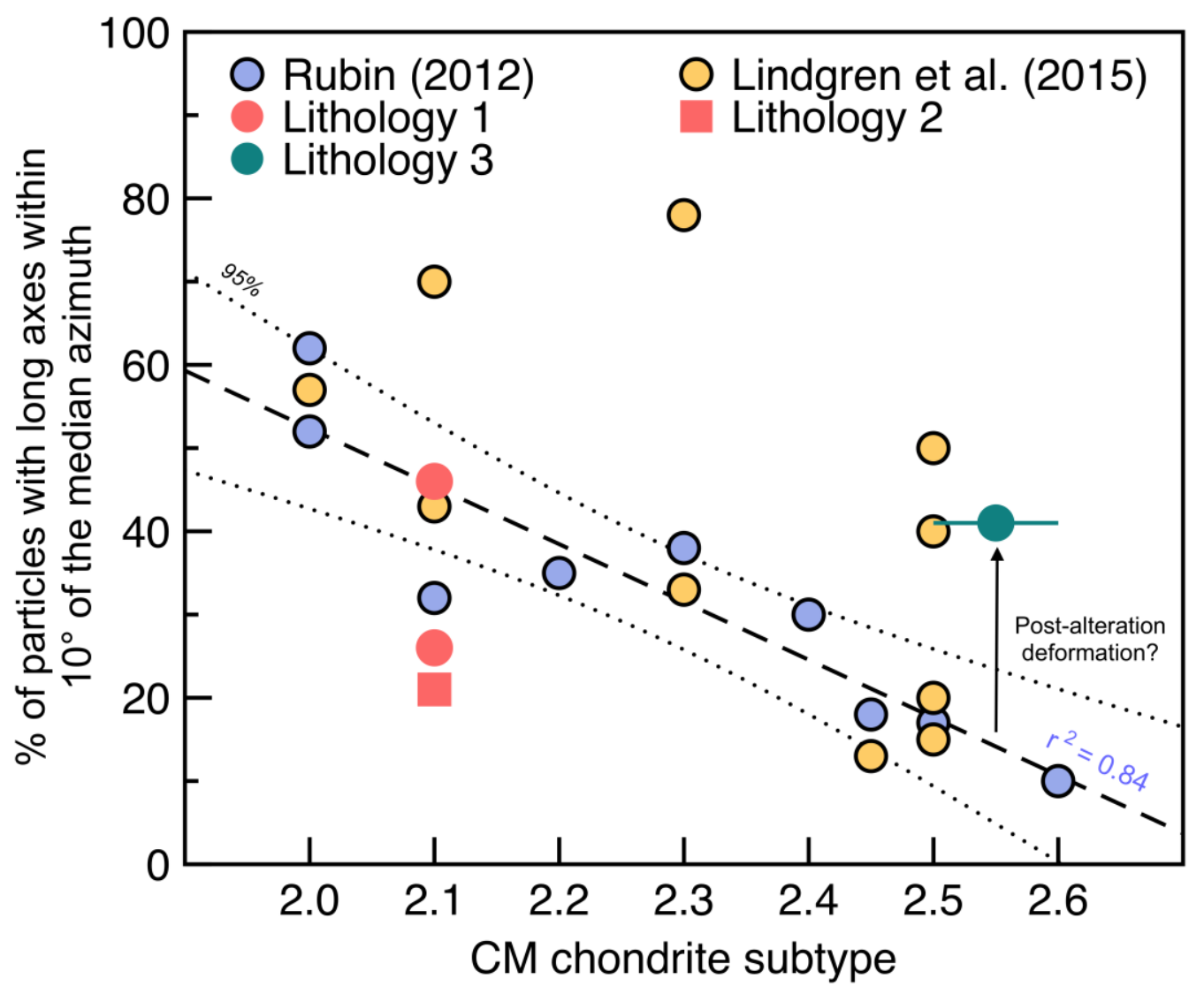

1219

Figure 12 

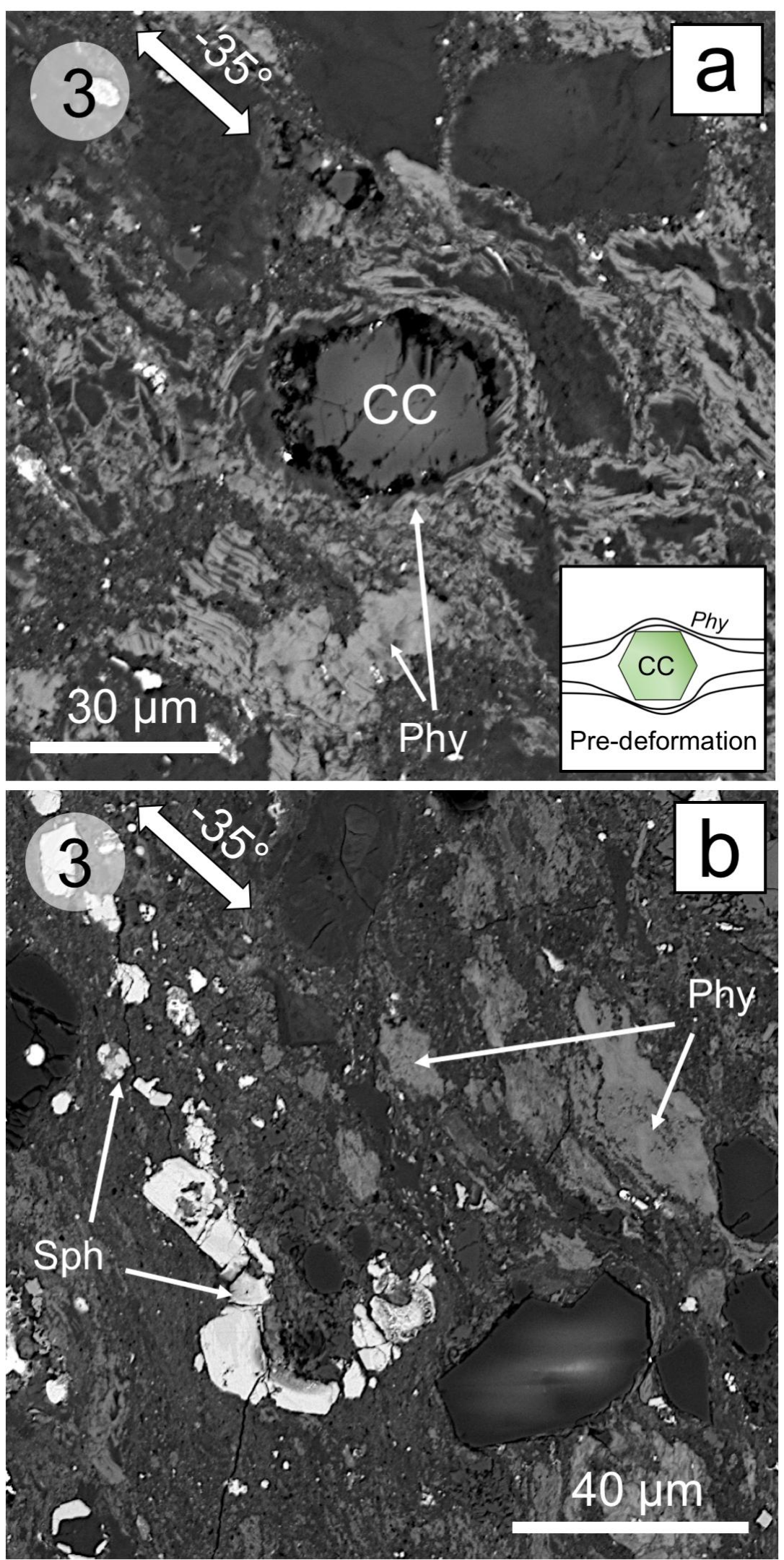

Figure 13 


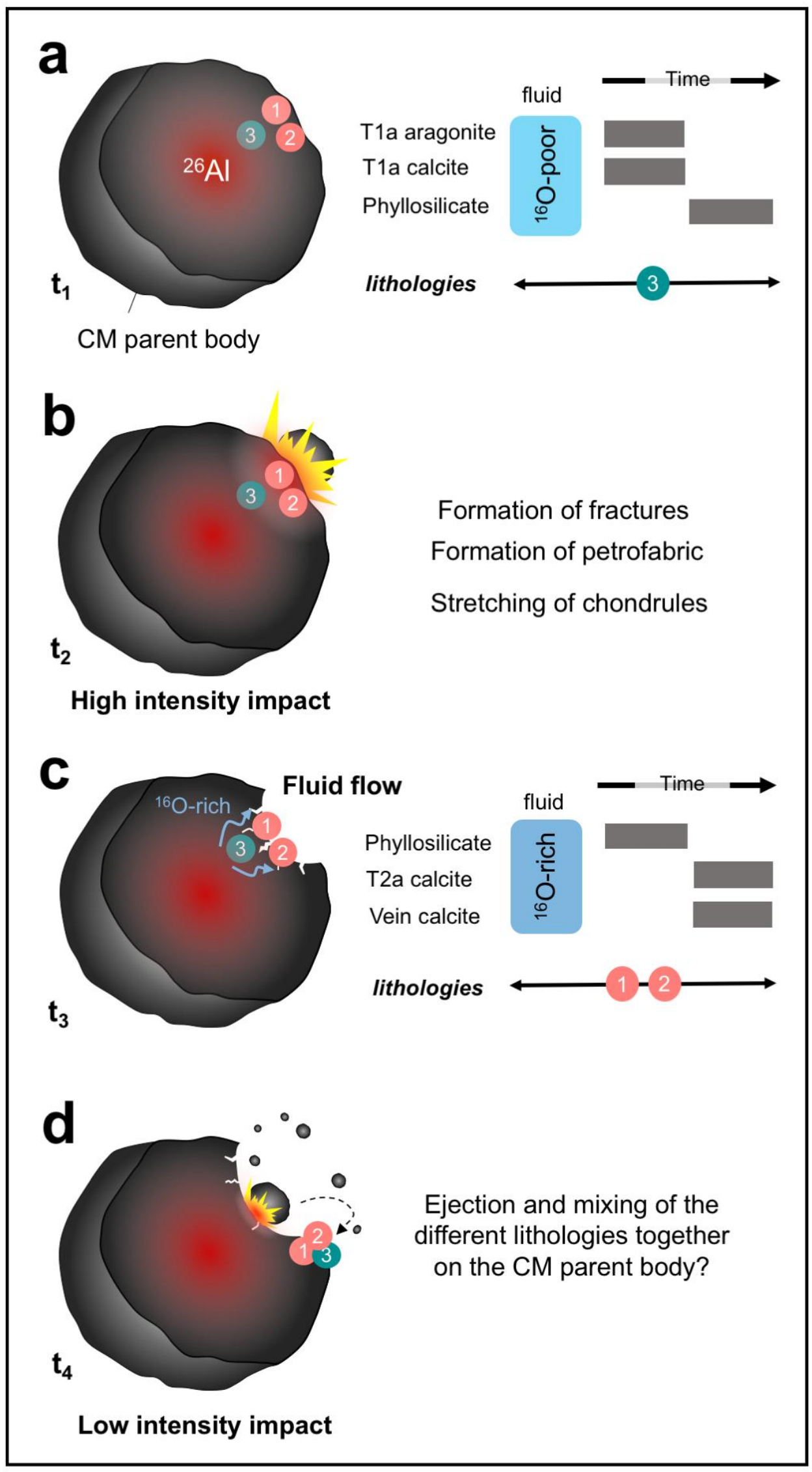




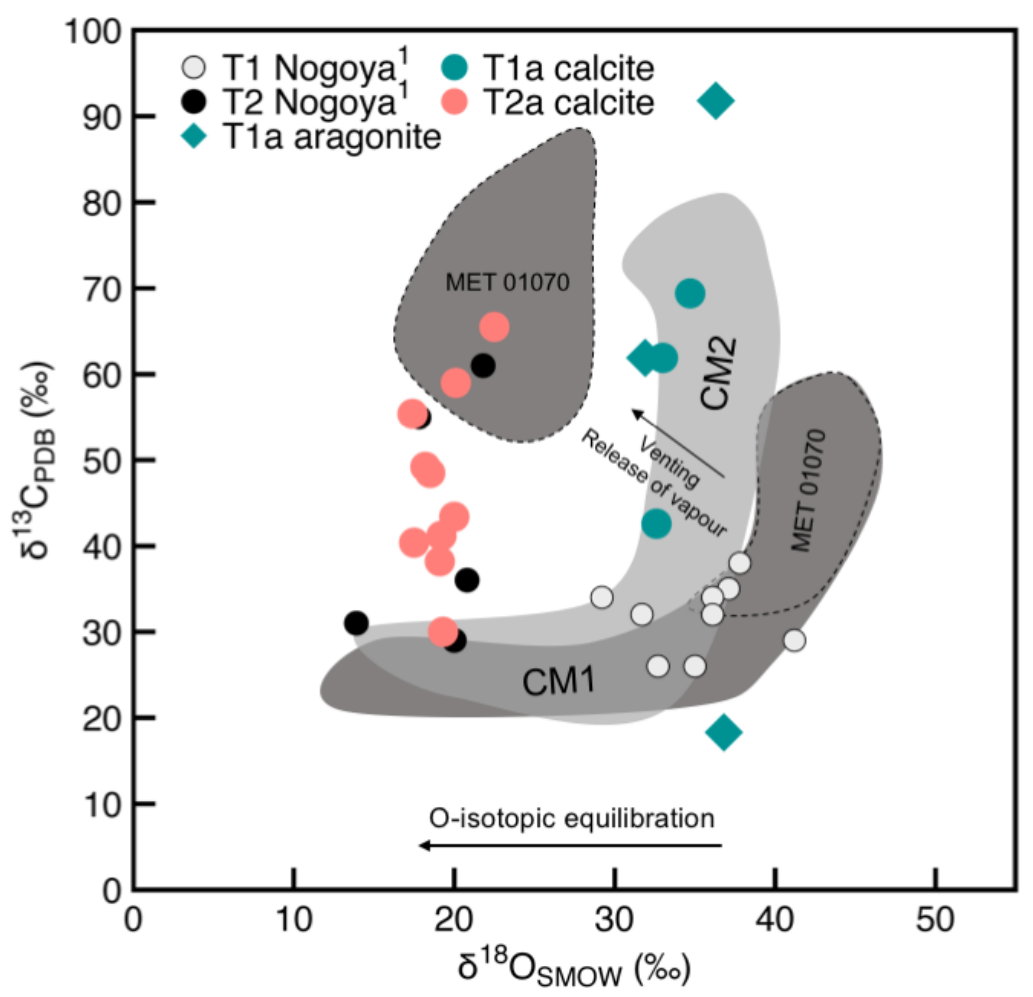



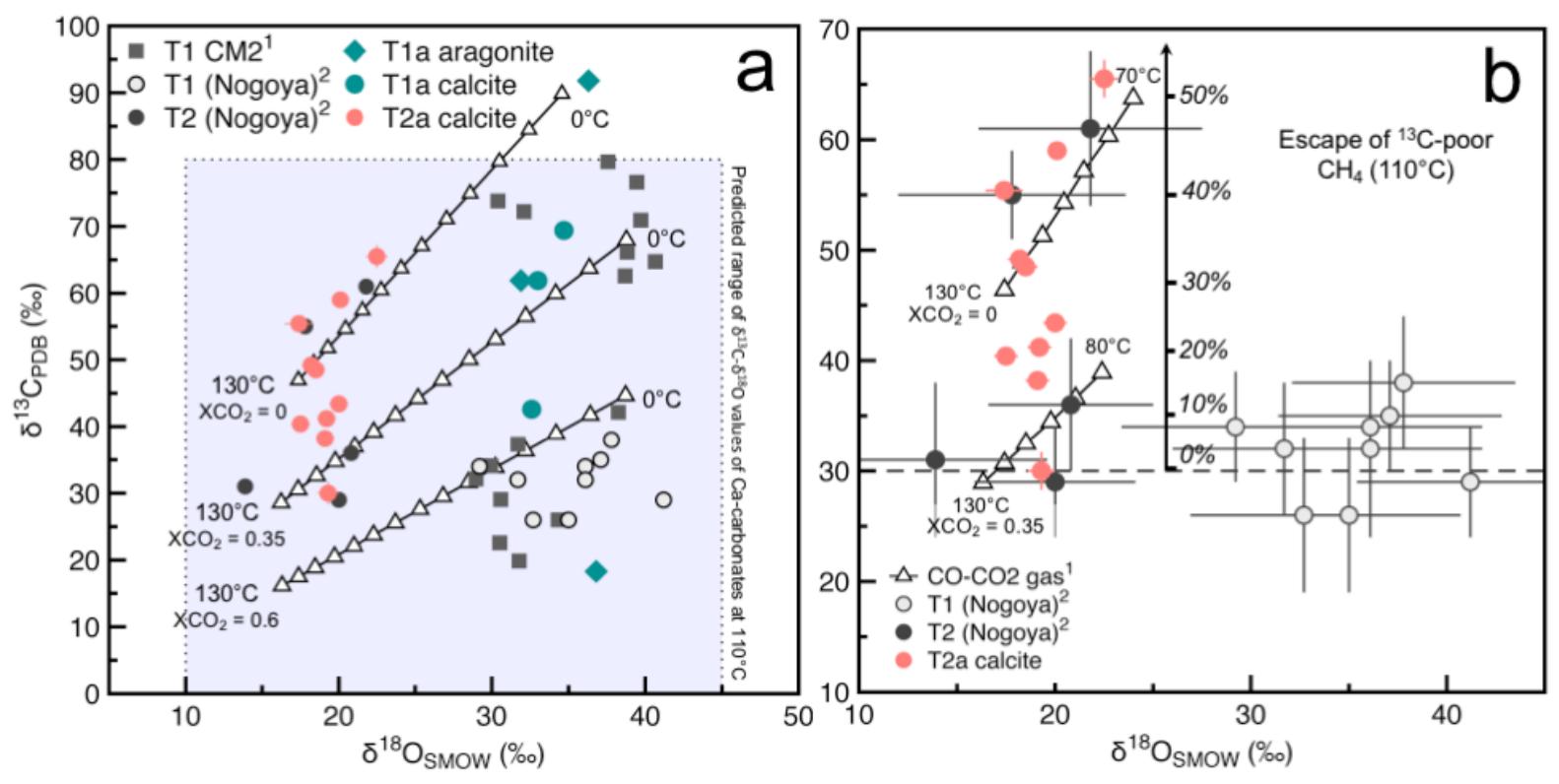

1228

Figure 16

1229 


\begin{tabular}{cccc}
\hline Lithologies & L1 $(\mathbf{n = 5 1 0})$ & L2 $(\mathbf{n}=\mathbf{5 0 1})$ & L3 $(\mathbf{n}=\mathbf{2 5 1})$ \\
\hline Surface counting $\left(\mathrm{mm}^{2}\right)$ & 6 & 4 & 2 \\
Matrix (vol. \%) & 60.15 & 62.3 & 68 \\
Chondrule (vol. \%) & 30 & 34.7 & 23.9 \\
Sulphide (vol. \%) & 8.6 & 1.6 & 5.2 \\
Ca-carbonate (vol. \%) & 1.2 & 1.4 & 2.4 \\
Metallic Fe-Ni (vol. \%) & $\sim 0.05$ & Not detected & $\sim 0.5$ \\
Chondrule mesostasis & Phyllosilicate & Phyllosilicate & Phyllosilicate \\
Mafic silicate into chondrule & Partially altered & Partially altered & Unaltered \\
Type of Ca-carbonate & T2a and veins & T2a & T1a \\
\hline
\end{tabular}

Table 1. Modal abundance of mixture of phases and components (in vol. \%) determined by 


\begin{tabular}{ccccc}
\hline & Mean & StDev & Min & Max \\
\hline & \multicolumn{4}{c}{$(\mathrm{n}=61)$} \\
\hline Primary axis length $(\mu \mathrm{m})$ & 249 & 109 & 82 & 531 \\
Secondary axis length $(\mu \mathrm{m})$ & 187 & 79 & 71 & 447 \\
Tertiary axis length $(\mu \mathrm{m})$ & 132 & 48 & 61 & 300 \\
${\text { Volume }\left(\mathrm{mm}^{3}\right)}_{\text {Aspect ratio }^{1}}$ & 0.03 & 0.04 & 0.002 & 0.2 \\
Elongation $^{2}$ & 1.87 & 0.46 & 1.11 & 3.34 \\
Flatness $^{3}$ & 1.34 & 0.26 & 1.01 & 2.07 \\
\hline
\end{tabular}

${ }^{1}$ Primary axis length/tertiary axis length ${ }^{2}$ Primary axis length/secondary axis length ${ }^{3}$ Secondary axis length/tertiary axis length

Table 2. Bulk best-fit ellipsoid measurements of dark-toned objects (interpreted as type I chondrules) in the CM Boriskino. 


\begin{tabular}{|c|c|c|c|c|c|c|c|c|c|c|c|}
\hline \# & Type & Polymorph & Lith. & $\delta^{18} O(\% o)$ & $2 \sigma$ & $\delta^{17} \mathrm{O}(\% \mathrm{o})$ & $2 \sigma$ & $\Delta^{17} \mathrm{O}(\%)$ & $2 \sigma$ & $\delta^{13} \mathrm{C}(\%)$ & $2 \sigma$ \\
\hline CC10 & $1 \mathrm{a}$ & Aragonite & (3)? & 36.8 & 0.8 & 18.3 & 0.5 & -0.8 & 0.8 & 18.3 & 0.6 \\
\hline $\mathrm{CC} 4$ & $1 \mathrm{a}$ & Aragonite & (3) & 36.3 & 0.7 & 17.8 & 0.5 & -1.1 & 0.7 & 91.8 & 0.8 \\
\hline CC6 & $1 \mathrm{a}$ & Aragonite & (3) & 33.4 & 1.2 & 16.4 & 0.7 & -1.0 & 1.1 & - & - \\
\hline CC5 & $1 \mathrm{a}$ & Aragonite & (3) & 31.9 & 0.6 & 15.6 & 0.6 & -0.9 & 0.7 & 61.9 & 1.4 \\
\hline CC15-1 & $1 \mathrm{a}$ & Calcite & (3) & 35.4 & 0.7 & 16.6 & 0.6 & -1.8 & 0.8 & 25.6 & 1.5 \\
\hline CC15-2 & $1 \mathrm{a}$ & Calcite & (3) & 29.8 & 0.7 & 15.2 & 0.5 & -0.4 & 0.7 & 59.6 & 0.5 \\
\hline CC3 & $1 \mathrm{a}$ & Calcite & (3) & 33 & 0.7 & 16.6 & 0.6 & -0.6 & 0.8 & 61.9 & 1.2 \\
\hline CC7-1 & $1 \mathrm{a}$ & Calcite & (3) & 34.7 & 0.7 & 16.7 & 0.6 & -1.3 & 0.7 & 71.6 & 0.9 \\
\hline $\mathrm{CC} 7-2$ & $1 \mathrm{a}$ & Calcite & (3) & - & - & - & - & - & - & 67.2 & 0.9 \\
\hline $\begin{array}{l}\text { Mean } \\
\text { StDev }\end{array}$ & & & & $\begin{array}{c}33.9 \\
2.4 \\
\end{array}$ & & $\begin{array}{c}16.7 \\
1\end{array}$ & & $\begin{array}{c}-1.0 \\
0.4 \\
\end{array}$ & & $\begin{array}{l}\mathbf{5 5 . 8} \\
25.7 \\
\end{array}$ & \\
\hline CC6-3 & $2 a$ & Calcite & (1) & 22.5 & 0.7 & 8.2 & 0.6 & -3.5 & 0.8 & 56.8 & 0.9 \\
\hline CC6-2 & $2 a$ & Calcite & (1) & - & - & - & - & - & - & 68.9 & 0.6 \\
\hline CC6-1 & $2 a$ & Calcite & (1) & - & - & - & - & - & - & 70.7 & 1.3 \\
\hline CC11 & $2 a$ & Calcite & (2) & 20.1 & 0.5 & 8.8 & 0.6 & -1.7 & 0.7 & 59 & 0.4 \\
\hline $\mathrm{CC} 7$ & $2 a$ & Calcite & (1) & 20 & 0.6 & 7.3 & 0.5 & -3.1 & 0.7 & 43.4 & 0.5 \\
\hline CC9 & $2 a$ & Calcite & (1) & 19.3 & 0.7 & 7.6 & 0.6 & -2.4 & 0.8 & 30 & 1.7 \\
\hline CC12 & $2 a$ & Calcite & (2) & 19.2 & 0.7 & 6.8 & 0.7 & -3.2 & 0.8 & - & - \\
\hline CC5 & $2 a$ & Calcite & (1) & 19.2 & 0.6 & 7.4 & 0.5 & -2.6 & 0.7 & 41.2 & 0.6 \\
\hline CC3 & $2 a$ & Calcite & (1) & 19.1 & 0.6 & 6.7 & 0.5 & -3.3 & 0.7 & 38.2 & 0.6 \\
\hline CC10 & $2 a$ & Calcite & (2) & 18.6 & 0.7 & 7.2 & 0.6 & -2.4 & 0.8 & - & - \\
\hline $\mathrm{CC} 1$ & $2 a$ & Calcite & (1) & 18.5 & 0.6 & 6.2 & 0.5 & -3.4 & 0.7 & 48.5 & 0.5 \\
\hline $\mathrm{CC} 14$ & $2 \mathrm{a}$ & Calcite & (2) & 18.2 & 0.6 & 7.2 & 0.6 & -2.2 & 0.7 & 49.2 & 0.6 \\
\hline CC8-2 & $2 a$ & Calcite & (1) & 17.6 & 0.5 & 8.6 & 0.5 & -0.6 & 0.7 & - & - \\
\hline CC8-1 & $2 a$ & Calcite & (1) & 17.2 & 0.8 & 7.1 & 0.7 & -1.8 & 0.9 & 55.4 & 0.5 \\
\hline $\mathrm{CC} 16$ & $2 \mathrm{a}$ & Calcite & (3) & 17.5 & 0.6 & 6.6 & 0.6 & -2.5 & 0.7 & 40.4 & 0.5 \\
\hline Mean & & & & 19.0 & & 7.4 & & -2.5 & & 50.1 & \\
\hline StDev & & & & 1.4 & & 0.8 & & 0.8 & & 12.4 & \\
\hline $\mathrm{CC} 2$ & Vein & Calcite & (1) & 16.9 & 0.6 & 6.7 & 0.5 & -2.0 & 0.7 & - & - \\
\hline
\end{tabular}

1286 Table 3. Mineralogies, petrographic types, and oxygen and carbon isotopic compositions of 1287 Boriskino Ca-carbonates. 